\title{
Unravelling changing sediment sources in a Mediterranean mountain catchment: a Bayesian fingerprinting approach
}

Koen D’Haen (1), Gert Verstraeten (1,2), Bert Dusar (1), Patrick Degryse (1,2), Jill Haex (1), Marc Waelkens $(2,3)$

(1) Department of Earth and Environmental Sciences, KU Leuven, Celestijnenlaan 200E box 2409, B-3001 Heverlee, Belgium (koen.dhaen@ees.kuleuven.be), (2) Center for Archaeological Science, KU Leuven, Belgium, (3) Archaeology Research Unit, KU Leuven, Belgium

\begin{abstract}
To determine the provenance of Holocene floodplain deposits of the Büğdüz catchment in southwest Turkey a Bayesian fingerprinting approach was used. An important requirement for any provenance study is that the potential sediment sources show sufficient spatial and compositional heterogeneity. The spatial distribution of potential sources, in this case the various lithologies present within the catchment, was mapped using field observations and ASTER and Quickbird satellite images. To distinguish the source lithologies a set of geochemical tracers was identified with the use of a Linear Discriminant Analysis. This optimum fingerprint was then used in the mixing model to determine the sediment provenance. The Bayesian mixing model uses Markov chain Monte Carlo random walks to determine the most probable source composition and mixing proportions. The uncertainty associated with the input data can be incorporated into the model through the prior probability distributions. The spread of the posterior probability distributions represents the uncertainty associated with the mixing proportion calculation. The main contrasts in provenance of the floodplain deposits reflect the spatial distribution of potential sediment sources throughout the catchment. There are, however, also important temporal variations in sediment provenance and lateral differences due to the nature of floodplain build-up. The observed spatial and temporal variability of sediment provenance gives a first indication that hill slope-channel and within-channel coupling relations are not uniform through the catchment and that different locations showed a distinct response to disturbances.
\end{abstract}


This manuscript has been published as:

D'Haen K, Verstraeten G, Dusar B, Degryse P, Haex J and Waelkens M. 2012 Unravelling changing sediment sources in a Mediterranean mountain catchment: a Bayesian fingerprinting approach. Hydrological Processes

\section{Introduction}

Climate changes and human activity have a profound impact on river systems (Macklin and Lewin, 2008). In the Mediterranean region intense human activity during the classical period (Hellenistic to Roman Period) has caused widespread erosion and alluviation. It has been shown by several studies that this coupling is not always straightforward, however, as it not only depends on the intensity of human activity, but also on the spatial patterns of land use change and internal geomorphic system controls (e.g. the spatial distribution of landforms impeding or enhancing sediment delivery). As a result, different locations within the landscape may respond differently to a single catchment disturbance event. In this study, the spatial and temporal sediment dynamics for the $264 \mathrm{~km}^{2}$ Büğdüz catchment are analyzed. The catchment is situated in the western part of the territory of the classical city of Sagalassos, in the southwest Turkish Taurus Mountain range (Waelkens et al., 1999). Previous sedimentological studies have shown that especially during the period 900 BCE-600 CE human activities triggered intense sedimentation in upland areas (Kaniewski et al., 2007b). However, the main objective of this study is to investigate how sediment dynamics have changed through space and time, and how the coupling between different parts of the Büğgüz catchment changed. One approach is the use field of observations to obtain sedimentation rates for various time periods (e.g. Hoffmann et al., 2009) and to calculate time-differentiated sediment budgets (e.g. Verstraeten et al., 2009b). However, several factors impede the construction of sediment budgets, in particular for Eastern Mediterranean river catchments (Dusar et al., 2011). Eastern Mediterranean river systems are generally characterised by cutand-fill floodplains making the application of alluvial architecture not straightforward. Furthermore, this cut and fill nature causes numerous terraces to be present within the alluvial plain. This complicates determining the alluvial plain width, which in turn increases the uncertainty on the calculated sediment budget. Although the radiocarbon database on hill slope and floodplain sedimentation for the wider region around Sagalassos is one of the most extensive in the entire Eastern Mediterranean (Dusar et al., 2012), it is still insufficient to obtain a catchment-wide chronology of sediment deposition that enables the establishment of a time-differentiated sediment budget. The general lack of datable organic matter within the alluvial sediments certainly remains problematic in this respect. Furthermore, although optical stimulated luminescence (OSL) dating could resolve this dating issue (e.g. Verstraeten et al., 2009a), a series of test samples taken from the Büğdüz floodplain sediment archive show that 
This manuscript has been published as:

D'Haen K, Verstraeten G, Dusar B, Degryse P, Haex J and Waelkens M. 2012 Unravelling changing sediment sources in a Mediterranean mountain catchment: a Bayesian fingerprinting approach. Hydrological Processes

OSL does not yield satisfactory results. Therefore, it is only possible to construct a very general sediment budget for i.e. the entire Holocene deposition within river valleys in the Eastern Mediterranean. Sediment fingerprinting enables the contributions of several spatially defined sediment sources to be quantified thus enlightening the black-box nature of the general sediment budget approach (D'Haen et al., 2012). The basic idea of the fingerprinting approach is that potential sediment sources possess properties that allow them to be distinguished and to quantify their contributions to the sediments in question to be determined. The potential sources are defined as end-members and the floodplain deposits are considered to be a mix of these end-members. The advantage of this approach is that it provides contributions from spatially defined areas and that it can be applied in cases where traditional geomorphic approaches to construct sediment budgets fail. It should be noted, however, that the fingerprinting approach requires potential sediment sources that are sufficiently heterogeneous in composition and spatial distribution, in order to yield meaningful provenance determinations. Although the sediment fingerprinting approach has often been applied to study contemporary suspended load fluxes (Collins et al., 1998; Davis and Fox, 2009; Gingele and De Deckker, 2005; Krishnappan et al., 2009; Minella et al., 2008) or recent historical floodplain deposits (Collins et al., 1997; Foster et al., 2007; Owens and Walling, 2002; Owens et al., 1999; Walling et al., 2003), only few studies are dedicated to (quantitatively) fingerprint long term river activity (e.g. Dearing et al., 2001; Hamlin et al., 2000). Nevertheless, the method shows great potential to study fluvial sediment fluxes on historical time scales (D'Haen et al., 2012).

\section{Materials and Methods}

\section{a) Study Area}

The area of interest is the $264 \mathrm{~km}^{2}$ Büğdüz catchment in the Taurus mountain range, SW Turkey. The most prominent topographic feature is the Beşparmak mountain range which reaches a peak height of about $2000 \mathrm{~m}$ a.s.l.. While the main Büğdüz river branch drains the Eastern and northern flanks of this mountain range, the largest tributary of the Büğdüz, the Yayla river, drains its western part. As the upland areas of Beşkavak and Bereket are located at respectively 1250 and $1450 \mathrm{~m}$ a.s.l. and the outlet of the Büğdüz into lake Burdur is situated at $850 \mathrm{~m}$ a.s.1., the Büğdüz river is characterized by a reasonable, but variable gradient. While the eastern part of the catchment is characterized by the presence of the 
This manuscript has been published as:

D'Haen K, Verstraeten G, Dusar B, Degryse P, Haex J and Waelkens M. 2012 Unravelling changing sediment sources in a Mediterranean mountain catchment: a Bayesian fingerprinting approach. Hydrological Processes

Beşparmak mountain range, the western part is dominated by badlands formed on lacustrine marl deposits. Several geomorphological processes can be identified that supply sediment to the river system. Which processes are dominant, is mainly dependent on topography and lithology. The soil developed on low to moderately sloping limestone is mainly affected by sheet, rill and to some extent gully erosion. The steep faces of the Beşparmak mountain range are, on the other hand, mainly prone to rock fall and debris flows. These processes formed the Pliocene to Pleistocene coarse grained deposits flanking the Beşparmak. The outskirts of the Beşparmak mountain range consist of more erodible material (coarse grained Pliocene/Pleistocene deposits and ophiolitic mélange) and are especially prone to gully erosion. Some of these gully channels have evolved to badland systems. Furthermore, they seem to be activated during discrete events, sometimes yielding large debris flows. The more gently dipping upland areas of Bereket and Beşkavak and the mudstone hills in the north are more affected by sheet and rill erosion, although gully erosion remains important. The western part of the catchment consists of soft marls and is characterized by severe badland formation, mainly linked to the subsidence of the Burdur graben.

As only a limited amount of proxies is available to evaluate Holocene climate changes in the study area itself, a resume of the most important changes in the Eastern Mediterranean is provided based on Dusar et al. (2011) and references therein, who evaluated the impact of several environmental factors on Holocene sediments dynamics in the Eastern Mediterranean. Although some general climatic trends can be observed through the Holocene, palaeoreconstructions are based on distinct proxies. Each of these proxies has its own strengths and drawbacks and will reflect the climatic signal in a particular way. The most used proxies are pollen data, oxygen and carbon isotopic ratios, lake levels and tree ring research.

In contrast to the Late Glacial climate, the early Holocene was characterized by a clearly warmer and wetter climate. This wetter climate persisted until ca. $5000 \mathrm{BCE}$, although fluctuations between wet and dry periods were present within this period. Thereafter, the impact of the Mediterranean Sea on the regional precipitation cycle enhanced and an overall trend of aridificaton significantly altered the Eastern Mediterranean environment. Nevertheless, considerable climate variability persisted through the Late Holocene. Finally, it should be noted that the Eastern Mediterranean displays a notable amount of regional climate variability. Numerous environmentally distinct areas have a local climate determined by 
This manuscript has been published as:

D'Haen K, Verstraeten G, Dusar B, Degryse P, Haex J and Waelkens M. 2012 Unravelling changing sediment sources in a Mediterranean mountain catchment: a Bayesian fingerprinting approach. Hydrological Processes

factors such as the distance to the Mediterranean sea, rain shadow effects, altitude and land cover.

For the Sagalassos territory in particular, a shift towards warmer and more humid conditions occurred around 1000 BCE. These conditions persisted until ca. 650/300 CE and were followed by a relatively drier period. The subsequent 1010-1280 CE moist trend and succeeding dry trend are consistent with other records in the Eastern Mediterranean (Bakker et al., 2012; Bakker et al., 2011).

The present day climate in the study area is typically Oro-Mediterranean. While the summers are warm and relatively dry, the winters are rather wet (Paulissen et al., 1993). From July till September arid conditions exist, whereas the rest of the year is reasonably humid. Furthermore, most of the precipitation falls in January and December, with a considerable amount of the precipitation falling as snow.

The present day vegetation cover consists of a mixture of Mediterranean forests (Pinus nigra, Juniperus excelsa, J. oxycedrus and to a lesser extent Quercus coccifera), shrub vegetation (Q. coccifera and sometimes J. oxycedrus), agricultural fields (Triticum durum, Cicer arietinum, Beta vulgaris, Medicago sativa and Helianthus annuus) and meadow-steppe-like grassland (grasses, meadow herbs and common fobs) (Bakker et al., 2012; Bakker et al., 2011).

Regarding archaeological evidence of human settlement within the Büğdüz catchment, several sites were detected in the vicinity of modern villages. These sites range from relicts of farms, tombs or fortresses to whole villages. Most settlements date from the Roman Imperial period (c. $25 \mathrm{BCE}-450 / 475 \mathrm{CE}$ ), while some sites already emerged in the early Bronze Age (c. 3000-2000 BCE) in the vicinity of Bereket. It should be mentioned, however, that only the area around Bereket was surveyed intensively.

\section{b) Lithological map}

The main objective of this study is to gain more insight into the spatial variation of sediment dynamics over time through the use of a sediment tracing approach. A primary requirement is that the potential sediment sources are spatially well defined. In this case potential sediment sources are defined by lithological differences, so it is important to have a detailed lithological map of the study area. Although there is a geological map available of the area the units on this map represent stratigraphic units rather than lithologies (Senel, 1997). That is why, 
This manuscript has been published as:

D'Haen K, Verstraeten G, Dusar B, Degryse P, Haex J and Waelkens M. 2012 Unravelling changing sediment sources in a Mediterranean mountain catchment: a Bayesian fingerprinting approach. Hydrological Processes

starting from the existing geological map, a new lithological map was created. The lithologies (e.g. potential sediment sources) that were distinguished are limestone, ophiolitic mélange, conglomerate, ophiolitic debris (e.g. reworked ophiolitic material), mudstone, olistostrome and marl. The updated lithological map of the Büğdüz catchment is shown in Figure 1. Several proxies were used to construct this lithological map. The first proxy consists of field observations pin-pointed by GPS measurements in combination with topsoil samples to assess the compositional differences between the mapped units. In total 461 GPS points were recorded and 217 topsoil samples were taken.

A second proxy consists of a Quickbird image which allowed to map limestone outcrops and the extent of the alluvial plain. Moreover, the occurrence of colour differences allows to distinguish certain lithologies . For instance, marls can easily be recognized by their bright white colour, whereas orange is an indicator for the presence of conglomerate and greenish soils suggest the presence of ophiolitic material.

The third proxy was a maximum likelihood classification image of the different occurring lithologies using Advanced Spaceborne Thermal Emission and Reflection Radiometer (ASTER) 1B data acquired on 18 October 2001. The ASTER data consist of 3 VNIR (Visible and Near Infrared Radiometer) bands with a $15 \mathrm{~m}$ resolution, 6 SWIR (Short Wave Infrared Radiometer) bands with a 30m resolution and 5 TIR (Thermal Infrared Radiometer) bands with a $90 \mathrm{~m}$ resolution. Prior to analysis, the spectral signal of the vegetation cover was suppressed based on the VNIR bands information. To perform the classification, several "regions of interest" (circular areas with a diameter of 50m) were identified on each lithology to calibrate and validate the maximum likelihood classification. As the olistostrome unit covers only a small area and is not clearly distinct from other lithologies, it was excluded from the classification. To eliminate singular different pixels within larger homogeneously classified areas a majority analysis was performed. To evaluate this supervised classification, a confusion matrix was constructed, comparing the classification with ground truth data (Table 1). The overall accuracy is $74 \%$ with a kappa coefficient of 0.69 and the accuracy for each lithological class is depicted in Table 2. The kappa coefficient is an alternative measure for the accuracy of the classification

$$
\kappa=\frac{\mathrm{N} \sum_{\mathrm{k}} \mathrm{CM}_{\mathrm{kk}}-\sum_{\mathrm{k}} \mathrm{CM}_{\mathrm{k} \Sigma} \mathrm{CM}_{\Sigma \mathrm{k}}}{\mathrm{N}^{2}-\sum_{\mathrm{k}} \mathrm{CM}_{\mathrm{k} \Sigma} \mathrm{CM}_{\Sigma \mathrm{k}}}
$$


This manuscript has been published as:

D'Haen K, Verstraeten G, Dusar B, Degryse P, Haex J and Waelkens M. 2012 Unravelling changing sediment sources in a Mediterranean mountain catchment: a Bayesian fingerprinting approach. Hydrological Processes

with $\mathrm{N}$ the total number of pixels in all ground truth classes and $\mathrm{CM}$ the confusion matrix.

The producer accuracy indicates the power of the classifier to put a pixel in a class, given that the pixel is actually in that class. The user accuracy on the other hand represents the probability that a classified pixel is in fact in the specified class. While for most lithologies the classification yields reasonable results, the accuracy of the conglomerate unit is rather poor. As indicated in the confusion matrix (Table 1) this is mainly due to an areal overestimation of the ophiolitic mélange unit. The maximum likelihood classification image was mainly used to map areas where other data was missing, e.g. no field observations and no distinctive Quickbird image.

c) Sampling and analysis

During several summer field campaigns (2007-2010) topsoil samples of potential sediment sources were collected and cores were drilled along cross sections in the floodplain. The locations of the cross sections are indicated on the lithological map (Figure 1) and the river long profile (Figure 2). Regarding the source groups, 39 topsoil samples were taken of limestone, 27 of marl, 66 of conglomerate, 41 of ophiolitic debris, 20 of mudstone, 6 of olistostrome and 18 of ophiolitic mélange. The results presented here concern 20 cores along 4 river sections (Figure 1). In this case sediment accumulation in the central part of the Büğdüz catchment was of main interest as this region is the main sink of sediment in the entire catchment. The cores range from 3 to $8 \mathrm{~m}$ in depth and are expected to represent sediment deposited during the last few thousand years. This was validated with 15 radiocarbon ages that were retrieved from the cores, as shown on the profiles (Figures 6 -9). All samples were oven dried, boiled in distilled water to disperse soil aggregates and subsequently wet sieved to retrieve the silt and clay fraction $(<63 \mu \mathrm{m})$. The fine material retrieved by sieving was ground using a Spex mill to obtain a homogenous sample. Of each ground sample $500 \mathrm{mg}$ was dissolved in $10 \mathrm{~mL}$ Aqua Regia $\left(1 \mathrm{HNO}_{3}(65 \%): 3 \mathrm{HCl}(37 \%)\right.$ ). Concentrations of 18 elements (Al, Ba, Ca, Co, Cr, Cu, Fe, K, Mg, Mn, Na, Ni, P, Pb, Sr, Ti, $\mathrm{V}, \mathrm{Zn}$ ) were determined with ICP-OES. In each batch (about 30 samples) 2 reference samples were included to monitor the precision (reproducibility) of the method. 
This manuscript has been published as:

D'Haen K, Verstraeten G, Dusar B, Degryse P, Haex J and Waelkens M. 2012 Unravelling changing sediment sources in a Mediterranean mountain catchment: a Bayesian fingerprinting approach. Hydrological Processes

d) Fingerprinting approach

To link sediment sources and sinks, potential sediment sources are regarded as end members in the sediment fingerprinting approach. The sediment itself is considered to be a mixture of these end members (sediment sources) and the contributions of potential sediment sources to the sediment can be reconstructed with the use of a specific set of tracers or fingerprints. An outline of the fingerprinting approach applied here is presented in Figures 3 and 4. It basically consists of two parts. At first the optimum fingerprint, the set of tracers that best discriminates potential sources, is identified. Secondly, the tracers that are part of the optimum fingerprint are used in a multivariate mixing model to determine the provenance of the floodplain deposits.

Optimum fingerprint

A crucial step in any provenance study is the identification of distinctive fingerprints for potential sediment sources. To do so the approach outlined by Collins et al. (1996) was used (Figure 3). The most striking differences can be observed by plotting several tracers or the first components of a Principal Component Analysis against each other. However, to identify the geochemical tracers that are significantly different between the sources the nonparametric Kruskal Wallis test was used. Given these significantly different tracers, the smallest subset was determined that best discriminates between the different sources, a so called optimum fingerprint. This subset was defined using of a stepwise linear discriminant analysis procedure based on the minimisation of Wilks' Lambda. The p-value of the Fstatistic of the partial Wilk's lambda was used a decision criterion in the stepwise procedure, with a decision level of 0.2 (the default). Because this multivariate technique requires normally distributed data and is sensitive to outliers, the tracer data were transformed with the centred log ratio (clr) transformation (Aitchison, 1986).

$$
\operatorname{clr}(X)=\left[\ln \frac{x_{1}}{g(X)} ; \ldots ; \ln \frac{x_{D}}{g(X)}\right] \quad g(X)=\sqrt[D]{x_{1} \ldots x_{D}}
$$

\section{Bayesian mixing model}

In general the optimum fingerprint is used in a multivariate linear mixing model to calculate the contributions of the potential sources to the alluvial sediment. Because there are generally 
This manuscript has been published as:

D'Haen K, Verstraeten G, Dusar B, Degryse P, Haex J and Waelkens M. 2012 Unravelling changing sediment sources in a Mediterranean mountain catchment: a Bayesian fingerprinting approach. Hydrological Processes

more tracers than sources, this is basically an over determined linear system, constrained by the requirements of the mixing proportions to lie between 0 and 1 and sum up to 1 . For each core a system with $n$ samples, $s$ sources and $t$ tracers can be constructed in which a $(n \times t)$ matrix containing the sediment composition of the core $(\mathrm{C})$ is approximated by multiplying a $(n \times s)$-matrix containing mixing proportions $(\mathrm{X})$ with a $(s \times t)$-matrix containing the source composition $(\mathrm{S})$ :

$$
\begin{aligned}
& \mathrm{X}_{n \times s} \mathrm{~S}_{s \times t} \stackrel{\tilde{=}}{\mathrm{C}_{n \times t}} \\
& {\left[\begin{array}{ccc}
x_{11} & \cdots & x_{1 s} \\
\vdots & \ddots & \vdots \\
x_{n 1} & \cdots & x_{n s}
\end{array}\right]\left[\begin{array}{ccc}
s_{11} & \cdots & s_{1 t} \\
\vdots & \ddots & \vdots \\
s_{s 1} & \cdots & s_{s t}
\end{array}\right] \cong\left[\begin{array}{ccc}
c_{11} & \cdots & c_{1 t} \\
\vdots & \ddots & \vdots \\
c_{n 1} & \cdots & c_{n t}
\end{array}\right]}
\end{aligned}
$$

The core samples (C) are thus expressed as mixtures $(\mathrm{X})$ of the source end members $(\mathrm{S})$. To determine the contributions $(\mathrm{X})$ of potential sediment sources $(\mathrm{S})$ to the floodplain deposits (C) in the Büğdüz catchment the Bayesian Compositional Estimator (BCE) algorithm developed by Van den Meersche et al. (2008) was used (Figure 4). This algorithm is freely available and incorporated as a function in the open source statistical environment $R$ (http://www.r-project.org). Although this method was developed to determine microbial taxonomy, the problem outlined by Van den Meersche et al. (2008) is very similar to sediment fingerprinting in the sense that it also is an end-member problem.

The advantage of this Bayesian approach is that prior knowledge can be incorporated into the mixing model. The prior probability distribution of $\mathrm{S}$ is a $\gamma$ distribution based on the observed source means and relative standard deviation of the selected tracers, incorporating the withinsource variability of tracers in the model. The prior probability distribution of $\mathrm{C}$ is a $\gamma$ distribution based on the tracer values in the sediment core and the relative standard deviation of a reference sample. This way the instrumental precision ( e.g. reproducibility of the geochemical extractions and measurements) is taken into account. The prior probability distribution of $\mathrm{X}$ is a constant distribution determined by the least squares solution. As the mean and standard deviation of the source samples provide a good indicator of the actual source composition, the observed means might not be representative for the exact source composition at a certain location due to natural variation. Because a good knowledge of source composition is crucial for a proper provenance determination, the uncertainty of the source composition is dealt with in the model by sampling the posterior probability 
This manuscript has been published as:

D'Haen K, Verstraeten G, Dusar B, Degryse P, Haex J and Waelkens M. 2012 Unravelling changing sediment sources in a Mediterranean mountain catchment: a Bayesian fingerprinting approach. Hydrological Processes

distribution of the source composition $(\mathrm{S})$. As indicated by the system outlined above the BCE algorithm is applied on each core separately. This way the most probable source composition (S) is estimated for each locality, incorporating possible spatial variation of source composition into the mixing model. This, however, also implies that the source composition is assumed to show no temporal variation, which is consistent with the choice of different lithologies as potential sediment sources. The posterior probability distributions of $\mathrm{S}$ and $\mathrm{X}$ are sampled by Markov chain Monte Carlo (MCMC) random walks. The Bayesian method outputs a multidimensional probability distribution from which marginal distributions and summary statistics can be derived. The posterior probability distribution of $\mathrm{S}$ is constrained by the $10^{\text {th }}$ and $90^{\text {th }}$ quantiles of the observed source composition. To get good estimates for the input parameters (e.g. number of iterations, burn-in length,...) the approach outlined by Raftery and Lewis (1996) was applied. Moreover, to assess good mixing and convergence of the MCMC random walks, trace plots of all sampled parameters were inspected closely and multiple runs with different initial conditions were performed, which yielded similar results. It should be noted that only sources occurring upstream of the floodplain deposits in question are considered. So for instance marl, only occurring in the western part of the catchment, is not incorporated as a potential source in the mixing model for upper valley floodplain deposits in the eastern part of the catchment.

\section{Results}

a) Source discrimination

The main compositional differences between the potential sources are presented on a plot of the first two components of a Principal Component Analysis (Figure 5). A quick inspection of the data shows anomalies of several elements typical for particular sources. For instance, the ophiolitic mélange is characterised by high $\mathrm{Mg}, \mathrm{Co}, \mathrm{Cr}$ and $\mathrm{Ni}$ concentrations probably due to the presence of mafic minerals; limestone samples typically show high $\mathrm{Ba}, \mathrm{K}$ and $\mathrm{Pb}$ values indicating the presence of K-feldspar and marl samples have high $\mathrm{Sr}$ and $\mathrm{Mg}$ concentrations due to the presence of $\mathrm{Mg}$ rich carbonates. According to the Kruskal Wallis H-test all measured geochemical elements are significantly different between potential source groups. However, by minimising Wilks' Lambda a subset of 13 elements (Co, Sr, $\mathrm{Al}, \mathrm{Ca}, \mathrm{Mg}, \mathrm{K}, \mathrm{Cr}$, $\mathrm{Ba}, \mathrm{Fe}, \mathrm{V}, \mathrm{Ni}, \mathrm{Mn}, \mathrm{Zn}$ ) was identified as the optimum fingerprint, best discriminating potential sediment sources. This set of tracers allows $86 \%$ of all source samples to be 
This manuscript has been published as:

D'Haen K, Verstraeten G, Dusar B, Degryse P, Haex J and Waelkens M. 2012 Unravelling changing sediment sources in a Mediterranean mountain catchment: a Bayesian fingerprinting approach. Hydrological Processes

classified correctly (Table 3). While most source groups are well discriminated (76-96\% classified correctly), the olistostrome unit is defined poorly (33\% classified correctly). This could be due to the low number of samples (6) in this particular source group and the considerable amount of compositional overlap with limestone. As this unit only occurs in a restricted area in the eastern upstream part of the catchment, it is taken into account in nearby valley reaches, but neglected in sections downstream of the village of Kayaalt1 (Figure 1).

b) Provenance of floodplain deposits

To determine the provenance of a selection of the Büğdüz floodplain deposits, the Bayesian mixing model outlined above was applied to 20 cores along 4 profiles (Figures 6 -9). Due to the high number of variables included in the model, $5 \times 10^{6}$ to $30 \times 10^{6}$ iterations where required to yield stable results. Generally speaking the composition of the floodplain deposits reflects the spatial distribution of potential sediment sources (Figure 1 and Figures 6 - 9). For instance, the sediment along profile 07-Pro1 (Figure 6) is dominated by an input of conglomerate and ophiolitic debris, while downstream the contributions of mudstone (e.g. profile 07-Pro4) (Figure 7) and marl (e.g. profiles 09-Pro4 and 09-Pro5) (Figures 8 and 9) become increasingly important. This mainly indicates the importance of locally derived sediment. However, beside spatial variations, sediment sources have also changed through time. The degree of temporal variability is furthermore dependent on the location within the catchment.

The geomorphic setting of Profile 07-Pro1 is shown in Figure 10. It is characterised by an asymmetric valley with a steep south western hillside and a more gently sloping, less elevated north eastern valley edge. Several terrace levels are present north east of the river (Figure 6). A series of badland systems have developed on the gravel/conglomerate deposits surrounding this valley stretch. It is, however, not always clear how these systems connect to the main river at present, as a dense artificial drainage system has been constructed across the alluvial plain. The floodplain deposits are characterized by very coarse gravel beds at the bottom, overlain by relatively finer, gravel-rich deposits. In terms of provenance, this succession is mainly dominated by an alteration of more conglomerate rich and more ophiolitic debris rich deposits (Figure 6). The conglomerate is derived from local ravine systems, while the ophiolitic debris originates from the eastern flank of the Beşparmak, south of Kayaaltı. Peaks in ophiolitic debris seem to be more pronounced in older deposits. Furthermore, contributions from limestone and ophiolitic mélange seem to be generally higher in older deposits. Core 
This manuscript has been published as:

D'Haen K, Verstraeten G, Dusar B, Degryse P, Haex J and Waelkens M. 2012 Unravelling changing sediment sources in a Mediterranean mountain catchment: a Bayesian fingerprinting approach. Hydrological Processes

$07 \mathrm{C} 15$ shows, on the other hand, some seemingly contradictory results, as its top layer is significantly enriched in ophiolitic debris, in similarity with older deposits of cores 07C12 and 07C14. A possible explanation for this observation is that artificial drainage enhanced the connection between the river just past the village of Kayaaltı and this particular location.

Profile 07-Pro4 is located in a river section with a low valley slope and broad alluvial plain. It shows discrepancies between the central part of the floodplain and the borders (Figure 7). Moreover, the southern river bank (cores 07C01 and 07C03) shows different provenance signals. This could possibly be attributed to the cut and fill nature of the floodplain, with the central part (cores 07C30, 07C28, 07C27) representing the most recent floodplain deposits. These deposits are characterized by a succession of coarse grained deposits dominated by mudstone and ophiolitic debris overlain by finer, loamy deposits dominated by conglomerate. The amount of conglomerate subsequently decreases near the top.

Profiles 09-Pro4 and 09-Pro5 are characterized by the presence of several terraces. The main difference between the two profiles is that profile 09-Pro5 is located further in the badlands and therefore the deposits contain a larger proportion of marl. The geomorphic setting of profile 09-Pro4 is illustrated in Figure 11. The floodplain in this section is characterised by an old alluvial fan in the southeast, several colluvial fans originating from the marl badland systems and the presence of numerous terrace levels (Figure 8). Generally speaking, the deposits in this profile show a more or less uniform provenance signal, with a background of about $25 \%$ marl, although some more subtle provenance changes can be detected. It can be noticed that older alluvium generally contains higher proportions of limestone.

Profile 09Pro5 is located near the eastern edge of the actual marl badlands, where the valley slope increases and the floodplain width decreases considerably. Several terrace levels are present within this profile, possibly representing different cut and fill cycles (Figure 9). In general the sediment consists of about 50 to $60 \%$ marl, with some distinct packages with a higher contribution of conglomerate, a higher input of ophiolitic debris or a combined effect of more conglomerate and ophiolitic debris.

\section{Discussion}

a) Core selection for provenance determination

As illustrated in the previous sectionspatial variation throughout the catchment yields the largest contrast in sediment provenance. There is, however, also some lateral variability at 
This manuscript has been published as:

D'Haen K, Verstraeten G, Dusar B, Degryse P, Haex J and Waelkens M. 2012 Unravelling changing sediment sources in a Mediterranean mountain catchment: a Bayesian fingerprinting approach. Hydrological Processes

each valley cross-section dependent on the location of the sediment core within the floodplain. These variations are probably due to the cut-and-fill nature of the floodplain, creating several terrace levels, especially in the badland area (profiles 09-Pro4 and 09-Pro5) (Figures 8 and 9), and an asymmetric floodplain build-up (e.g. profile 07-Pro4) (Figure 7). To get a good idea of the geomorphology of the floodplain, several cores were drilled along profiles at several localities within the catchment. In the ideal case, all these cores could be analyzed in detail to yield a very detailed provenance map of the river valley fill. This would, however, require a huge amount of time and research funding. Moreover, not every core might be of primary interest concerning the objectives of the study. Therefore, it would be better to use the geomorphological information acquired for each profile to select a number of cores that are representative for the depositional phase(s) of interest. In this case, the focus is mainly on cores situated in the central part of the floodplain containing sediments deposited during of the last several millennia.

\section{b) Uncertainty}

There are several sources of uncertainty in the mixing model. First of all, sediment source compositions are not exactly known values, but a cluster of observations. Moreover, overlap between certain source groups makes it harder to distinguish between them. Secondly, several processes might affect tracers from the time the soil material is eroded until it is deposited in the floodplain and afterwards. Finally, the precision of the geochemical extraction and measurements introduces some uncertainty in the model. The advantage of Bayesian methods is that prior knowledge concerning uncertainty (spread of prior probability distributions) can be taken in account as it is included in the posterior output (spread of posterior probability distributions). In this case the observed within-source variability of the different tracers is incorporated as the standard deviation of the prior probability distribution of the source composition and the instrumental precision is incorporated as the standard deviation of the prior probability distribution of the sediment composition. To cope with spatial variation of source compositions, the most probable source composition is re-estimated based on the compositional information provided by the sediments in question, as they are assumed to be mixtures of the potential sediment sources. Even though it is very difficult to assess to what extent tracers might have been altered by erosion and post-depositional processes, these effects need to be taken into account. This is (at least partly) done by re-estimating the source composition. Furthermore, at least for the silt and clay fraction $(<63 \mu \mathrm{m})$ the effects of sorting 
This manuscript has been published as:

D'Haen K, Verstraeten G, Dusar B, Degryse P, Haex J and Waelkens M. 2012 Unravelling changing sediment sources in a Mediterranean mountain catchment: a Bayesian fingerprinting approach. Hydrological Processes

do not always have a significant effect on the provenance determination as has been illustrated by Fu et al. (2008). As for the effects of post-depositional alteration, Cossart et al. (2008) described a case where considerable post-depositional changes were observed, but the effect on the overall geochemistry was rather small.

In this case the main cause of uncertainty in the posterior probability distributions, however, is probably the overlap between potential sediment sources. This effect is especially pronounced when the overlapping sources are present in similar proportions. The advantage of the Bayesian approach presented here is that these uncertainties can be detected in the output. This is illustrated with a few examples of sediment samples of the different profiles (see Figures 6 - 9 and Figure 1 for the locations of the cores and profiles). The output of the model is presented as kernel density estimations of the posterior of each mixing proportion (plots on the diagonal in Figures 12 - 13) with an indication of the mean and standard deviation. To detect correlations between different mixing proportions, 2D-kernel estimations are plotted pair wise with an indication of the $\mathrm{R}^{2}$ value (biplots below diagonal on Figures 12 - 13). To summarise the provenance determination of each sample boxplots of all mixing proportions were created (plots in top right corner Figures 12 - 13). The results of sample SA2007-GV-205 (Figure 12) show the effects of overlapping source compositions discussed previously. As the PCA plot in Figure 5 indicates, there are similarities between limestone and conglomerate, ophiolitic debris and ophiolitic mélange and especially between conglomerate and ophiolitic debris. This phenomenon reflects itself in the results as higher correlations between the mixing proportions of less distinct sources, where high $\mathrm{R}^{2}$ values can indicate that sources are hard to distinguish. These correlations are mainly caused by the primary boundary condition that the mixing proportions should sum up to one. For sample SA-2007-GV-205 (Figure 12) the greatest correlation is between the mixing proportions of conglomerate and ophiolitic debris, resulting in larger uncertainties in the posterior (larger spread and standard deviations). In sample SA-2007-GV-738 (Figure 13) the contrast between the amount of conglomerate and ophiolitic debris present is much larger, resulting in less correlation and less uncertainty (smaller standard deviations).

To illustrate the uncertainty associated with the provenance determinations within a whole profile, the marginal posterior distributions of the mixing proportions of all sources in profile 07-Pro1 are depicted with boxplots (Figure 14). Although there is a certain amount of 
This manuscript has been published as:

D'Haen K, Verstraeten G, Dusar B, Degryse P, Haex J and Waelkens M. 2012 Unravelling changing sediment sources in a Mediterranean mountain catchment: a Bayesian fingerprinting approach. Hydrological Processes

uncertainty associated with the mixing proportions estimations, the general trends as interpreted from the mean mixing proportions (Figure 6) are still valid. Nevertheless, it is important to take the uncertainty into account when interpreting provenance determinations.

c) Connectivity within the Büğdüz catchment

As previously stated an important input from local sediment sources was recorded. To elucidate the connectivity between hill slopes and river channel and along the river channel itself, the provenance signal derived from the four profiles (Figures 6 -9) is compared to the upstream area each source covers (Table 4). The valley fill of profile 07-Pro1 mainly consists of conglomerate (5 - $90 \%)$ and ophiolitic debris (5 - $75 \%)$, whereas these units only cover respectively 28 and $14 \%$ of the upstream area. This indicates on the one hand a large input from local material (conglomerate) and on the other hand an enhanced connection in the past with the river stretch just south of Kayaalt1, where large gully systems developed on ophiolitic debris (Figure 1). Further downstream (profile 07-Pro4) conglomerate retains its dominant position (5 - $95 \%$ contribution), whereas the contribution of ophiolitic debris decreases (5 $50 \%$ ). Furthermore, a new sediment source comes into play, the mudstone unit located in the north. Given the restricted area the mudstone unit covers (about $20 \%$ at profile 07-Pro4), its contributions are rather high $(5-70 \%)$. Once more this indicates the relative importance of locally derived sediment. The coupling between hill slopes and river channel is, however, less explicit at this locality than near profile 07-Pro1. The valley is much wider near profile 07Pro4 and therefore only the larger tributary valleys connect to the river system. Furthermore, no distinct terrace levels are present at profile 07-Pro4. Profile 09-Pro4 located just before the confluence of the Büğdüz River with its most important tributary, the Yayla River, is characterised by a limited contribution from local sediment sources (e.g. marl). In comparison with the other profiles, this river stretch is well connected to upstream reaches. The coupling with local hill slopes is possibly hampered by the presence of numerous terraces. The origin of these terraces is, however, not always clear. Some levels show gravel deposits and seem to be fluvial, while others could have been constructed by man. Given the asymmetric shape of the valley, it seems like the river has cut through its own plain, progressively narrowing its bank full bed with a general southward migration. One explanation for this phenomenon is that this southward entrenchment is caused by the strike-slip component of the normal fault(s) bordering the Burdur graben (Price and Scott, 1994). A case where the formation of an asymmetric valley could be directly linked to the presence of a strike-slip fault is described 
This manuscript has been published as:

D'Haen K, Verstraeten G, Dusar B, Degryse P, Haex J and Waelkens M. 2012 Unravelling changing sediment sources in a Mediterranean mountain catchment: a Bayesian fingerprinting approach. Hydrological Processes

by Zhang et al. (2004). The different terrace levels are, however, not characterised by distinct provenance signals. This suggest the provenance of the deposits did not change much over time at this locality. Further downstream (profile 09-Pro5) local sediment sources (marl) gain importance. Whereas the upstream area covered by marl increases from $17 \%$ (profile 09Pro4) to $31 \%$ (profile 09-Pro5), the mean contribution of marl to the sediment increases from about $25 \%$ to 50-60\%. However, the deposits at several terrace levels do show distinct provenance signals at profile 09-Pro5 in contrast to profile 09-Pro4. This points out that the connectivity did change over time at this locality.

The results discussed here give a first indication that the hill slopes - river channel and withinriver channel coupling in the Büğdüz catchment changes through space and time. The spatial variability can be generally attributed to the spatial variation of geomorphologic characteristics through the Büğdüz catchment (e.g. floodplain width, steepness, entrenchment, etc.). For sediment dynamics changing over time, two main forcing mechanisms can be put forward. Changing sediment fluxes can be driven by changes in climate, land use or both. Whereas the Eastern Mediterranean experienced some important climatic changes over the last 10000 years, the most profound changes in sediment dynamics during the Holocene in the Eastern Mediterranean do not seem to be climatically driven. Initially sediment dynamics showed a clear response to climatic forcing. However, around c. 3000 - 2000 BCE the impact of man on the environment increased and sediment dynamics started to be closely linked to anthropogenic forcing (Dusar et al., 2011). Within the Sagalassos territory cumulative probability distributions (CPDs) and sedimentation rate (SR) modelling performed on a database containing 178 radiocarbon ages indicated high sedimentation rates during the initial major human disturbance of the landscape. After this initial pulse sedimentation rates decreased, which can probably be attributed to soil depletion (Dusar et al., 2012). For the Büğdüz catchment itself, previous geomorphological research in the upstream area around Bereket (see Figure 1 for location) indicated that the main sediment accumulation phase could be linked to a peak in cultivation between 40 BCE and 400 CE (Kaniewski et al., 2007a; Kaniewski et al., 2007b; Kaniewski et al., 2008).

For the central part of the catchment, the lack of a high resolution timeframe hampers a detailed evaluation of human induced changes in sediment dynamics. It is, however, assumed that the main terrace levels are of Pleistocene to Early Holocene age and can be mainly linked to tectonically induced base level changes, possibly superposed by climatic change. On the other hand, the radiocarbon ages retrieved from profile 07-Pro4 (Figure 7) do suggest a phase 
This manuscript has been published as:

D'Haen K, Verstraeten G, Dusar B, Degryse P, Haex J and Waelkens M. 2012 Unravelling changing sediment sources in a Mediterranean mountain catchment: a Bayesian fingerprinting approach. Hydrological Processes

of fast sediment accumulation (cores 07C32 and 10C07) during the Iron Age (c. 1200-333 BCE). This succession could represent an early phase of human disturbance. It is, however, somewhat surprising that during the main period of human settlement (Roman Imperial period, c. $25 \mathrm{BCE}-450 / 475 \mathrm{CE}$ ) no high sedimentation rates were recorded. This could be on the one hand attributed to soil depletion after the initial disturbance phase and/or on the other hand to improved agricultural practices during the Roman Imperial period.

\section{Conclusions}

A Bayesian mixing model based on Markov chain Monte Carlo random walks was successfully applied to determine the provenance of floodplain deposits of the Büğdüz catchment. The main advantage of this approach is the way of dealing with uncertainties. First of all, both the instrumental precision as the within-source variability of the tracers is integrated into the model through the prior probability distributions. Moreover, as the potential sediment sources are defined by clusters of observations and not by exactly known fixed points, the source composition is re-estimated for each locality to take in account natural spatial variability. Finally, the output of the mixing model provides a good means for uncertainty assessment as the spread of the posterior probability distribution represents the uncertainty associated with a particular calculated mixing proportion. Furthermore, sources that can be less well discriminated can be identified from the correlations between the mixing proportions. Using this mixing model to determine the provenance of four core profiles provided a first indication of the variation of sediment dynamics in the Büğdüz catchment through space and time. Although a detailed timeframe is lacking, this pointed out that different parts of the catchment reacted differently to catchment disturbances.

\section{Acknowledgements}

This research is part of a project funded by the Belgian Program on Interuniversity Poles of Attraction (IUAP 6/22) initiated by the Belgian State, Prime Minister's Office, Science Policy Programming, along with support from the Concerted Action of the Flemish Government (GOA project nr. 3H051017). The support of the Center for Archaeological Sciences at the KU Leuven is also gratefully acknowledged. Moreover, the authors would like to thank two anonymous reviewers for their highly constructive comments, which certainly improved the quality of this paper. 
This manuscript has been published as:

D'Haen K, Verstraeten G, Dusar B, Degryse P, Haex J and Waelkens M. 2012 Unravelling changing sediment sources in a Mediterranean mountain catchment: a Bayesian fingerprinting approach. Hydrological Processes 
This manuscript has been published as:

D'Haen K, Verstraeten G, Dusar B, Degryse P, Haex J and Waelkens M. 2012 Unravelling changing sediment sources in a Mediterranean mountain catchment: a Bayesian fingerprinting approach. Hydrological Processes

\section{Figures}

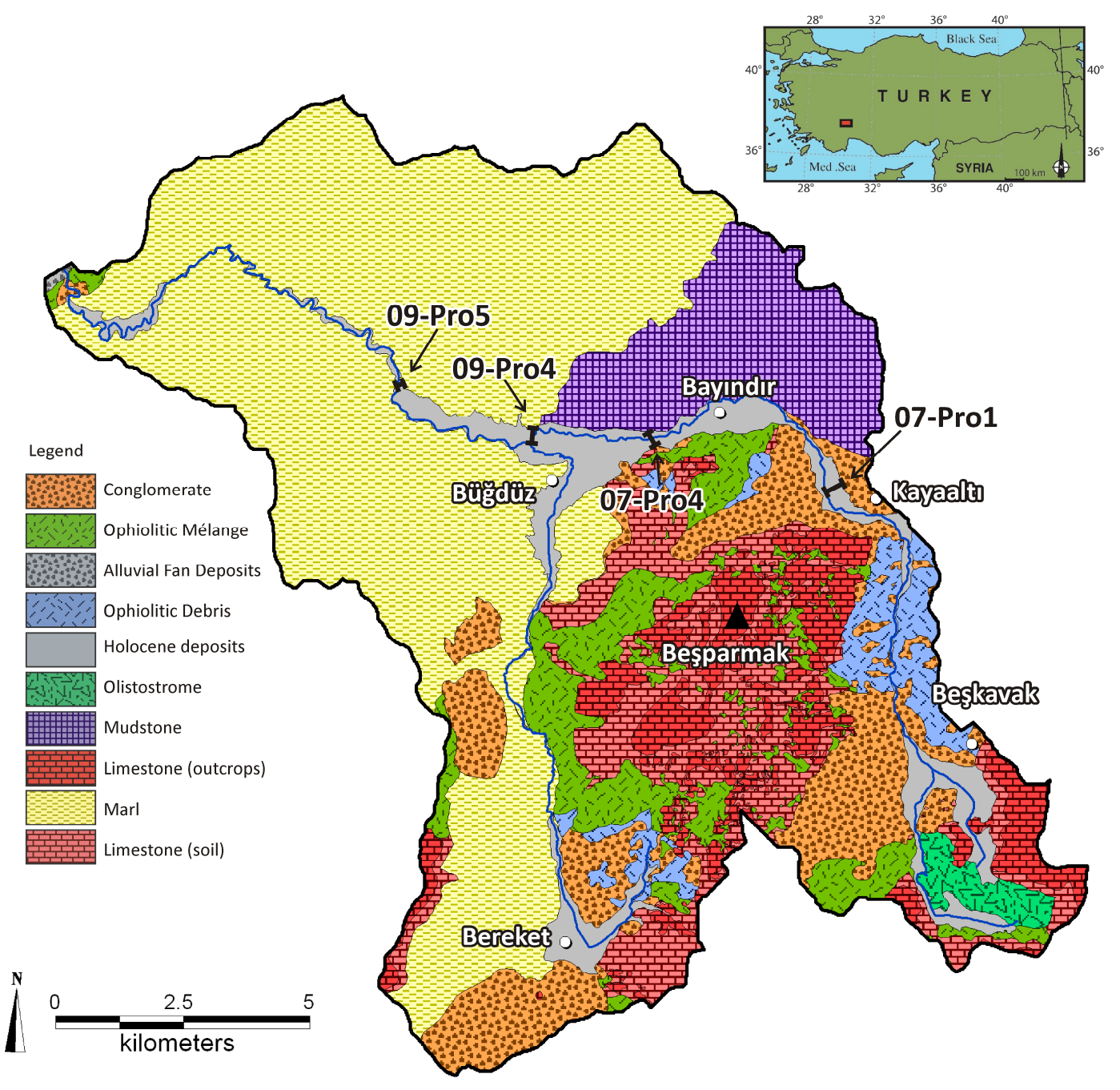

Figure 1 Lithological map of the Büğdüz catchment with indication of the sampled profiles. 
This manuscript has been published as:

D'Haen K, Verstraeten G, Dusar B, Degryse P, Haex J and Waelkens M. 2012 Unravelling changing sediment sources in a Mediterranean mountain catchment: a Bayesian fingerprinting approach. Hydrological Processes

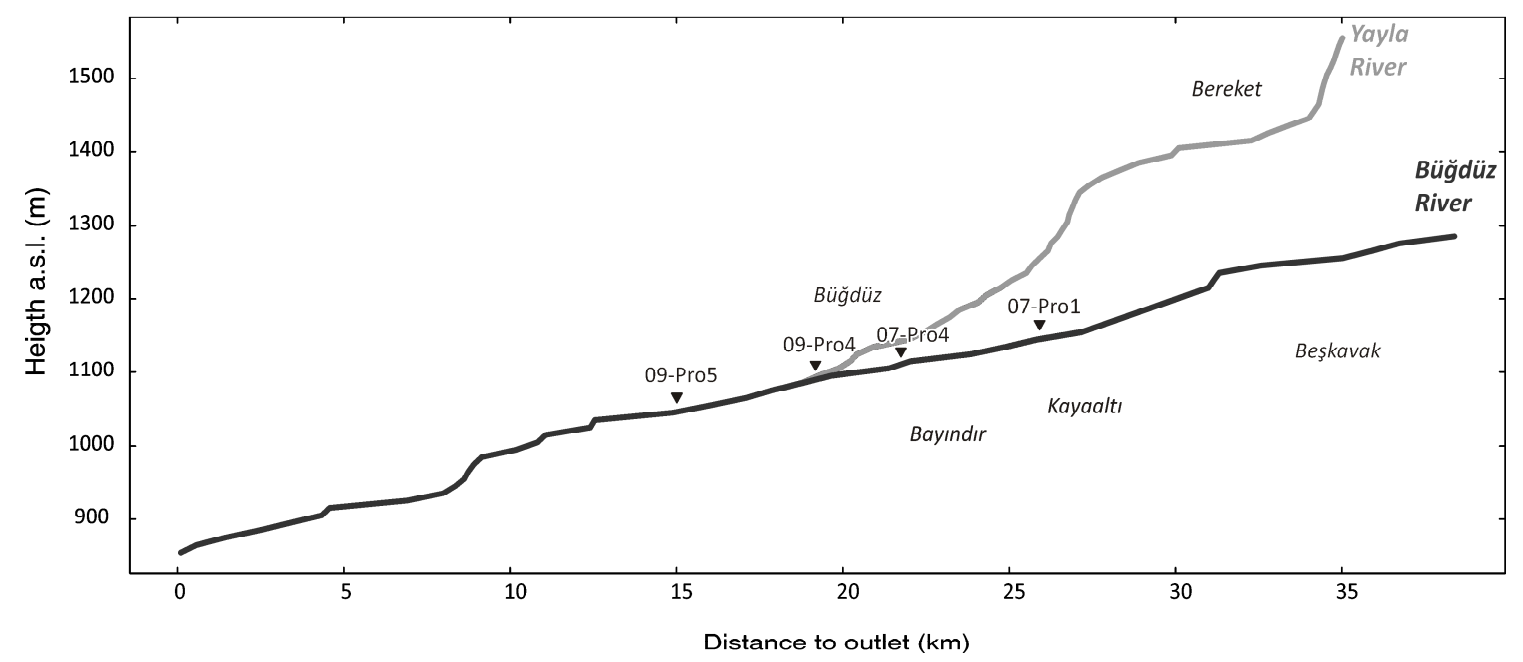

Figure 2 River long profile of Büğdüz and Yaya Rivers with an indication of core profiles and main villages. 
This manuscript has been published as:

D'Haen K, Verstraeten G, Dusar B, Degryse P, Haex J and Waelkens M. 2012 Unravelling changing sediment sources in a Mediterranean mountain catchment: a Bayesian fingerprinting approach. Hydrological Processes

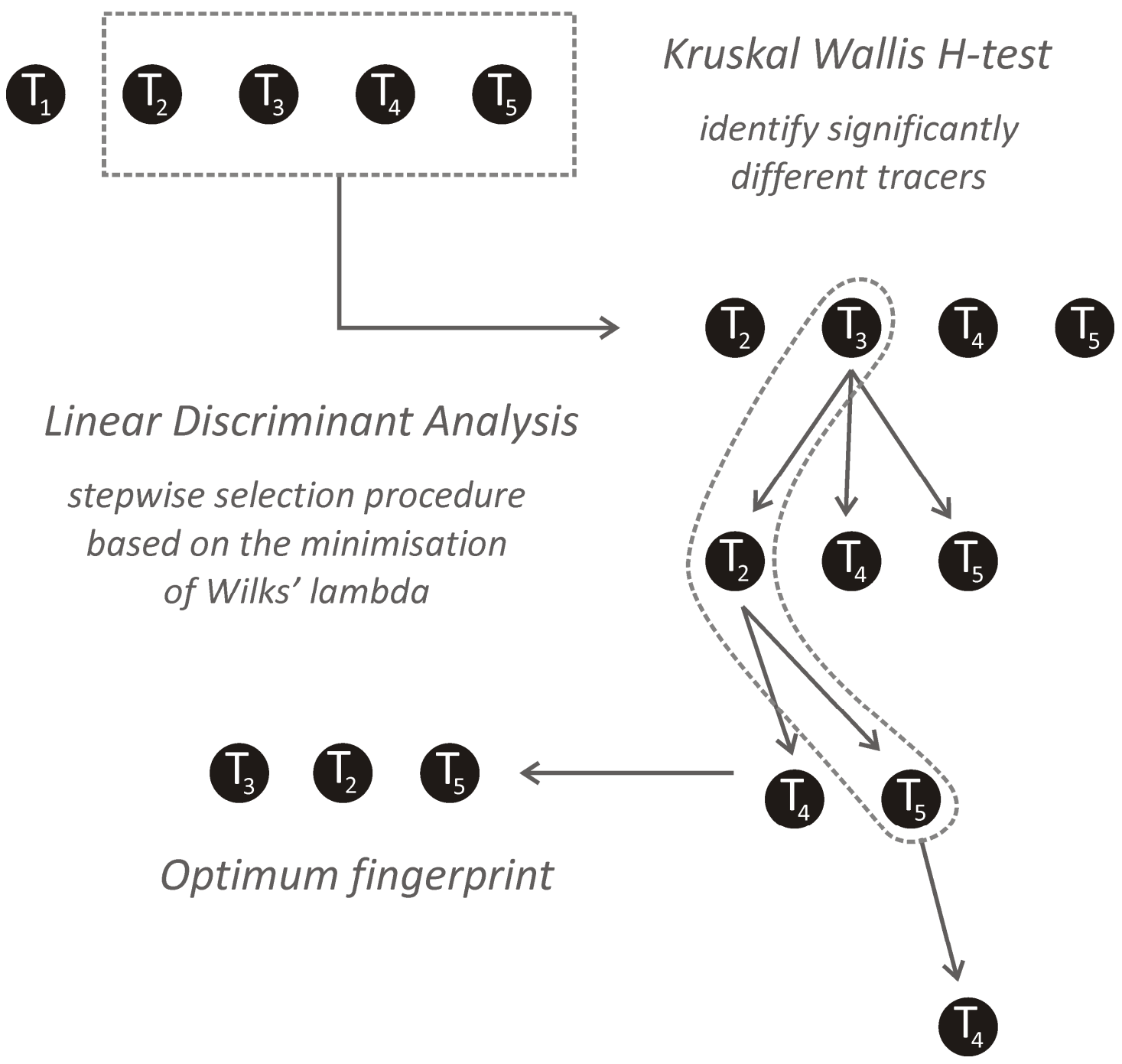

Figure 3 Determination of optimum fingerprint (based on Collins et al., 1996). 
This manuscript has been published as:

D'Haen K, Verstraeten G, Dusar B, Degryse P, Haex J and Waelkens M. 2012 Unravelling changing sediment sources in a Mediterranean mountain catchment: a Bayesian fingerprinting approach. Hydrological Processes

\section{Prior probability distributions}
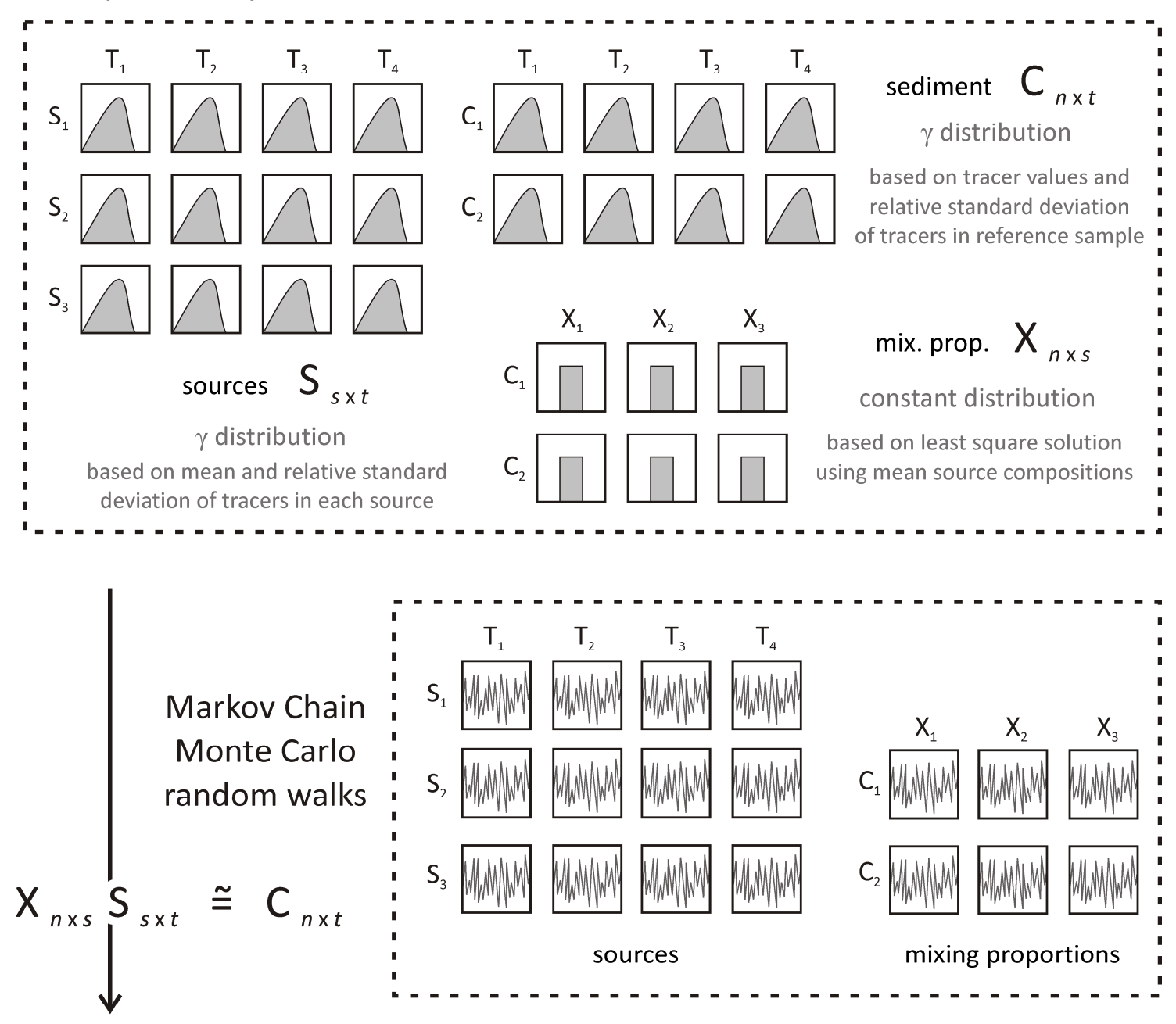

\section{Posterior probability distributions}

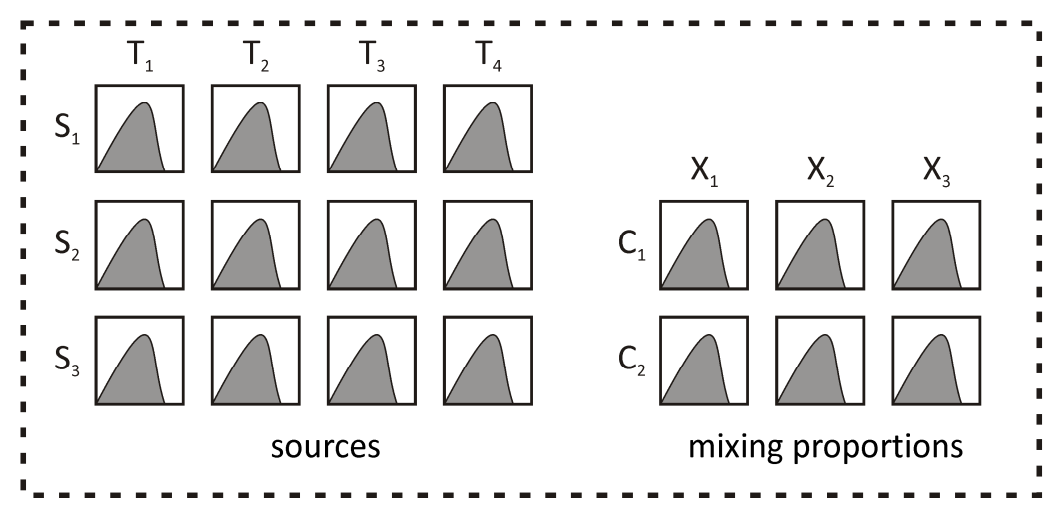

Figure 4 Schematic outline of the used Bayesian mixing model (based on Van den Meersche et al., 2008). 
This manuscript has been published as:

D'Haen K, Verstraeten G, Dusar B, Degryse P, Haex J and Waelkens M. 2012 Unravelling changing sediment sources in a Mediterranean mountain catchment: a Bayesian fingerprinting approach. Hydrological Processes
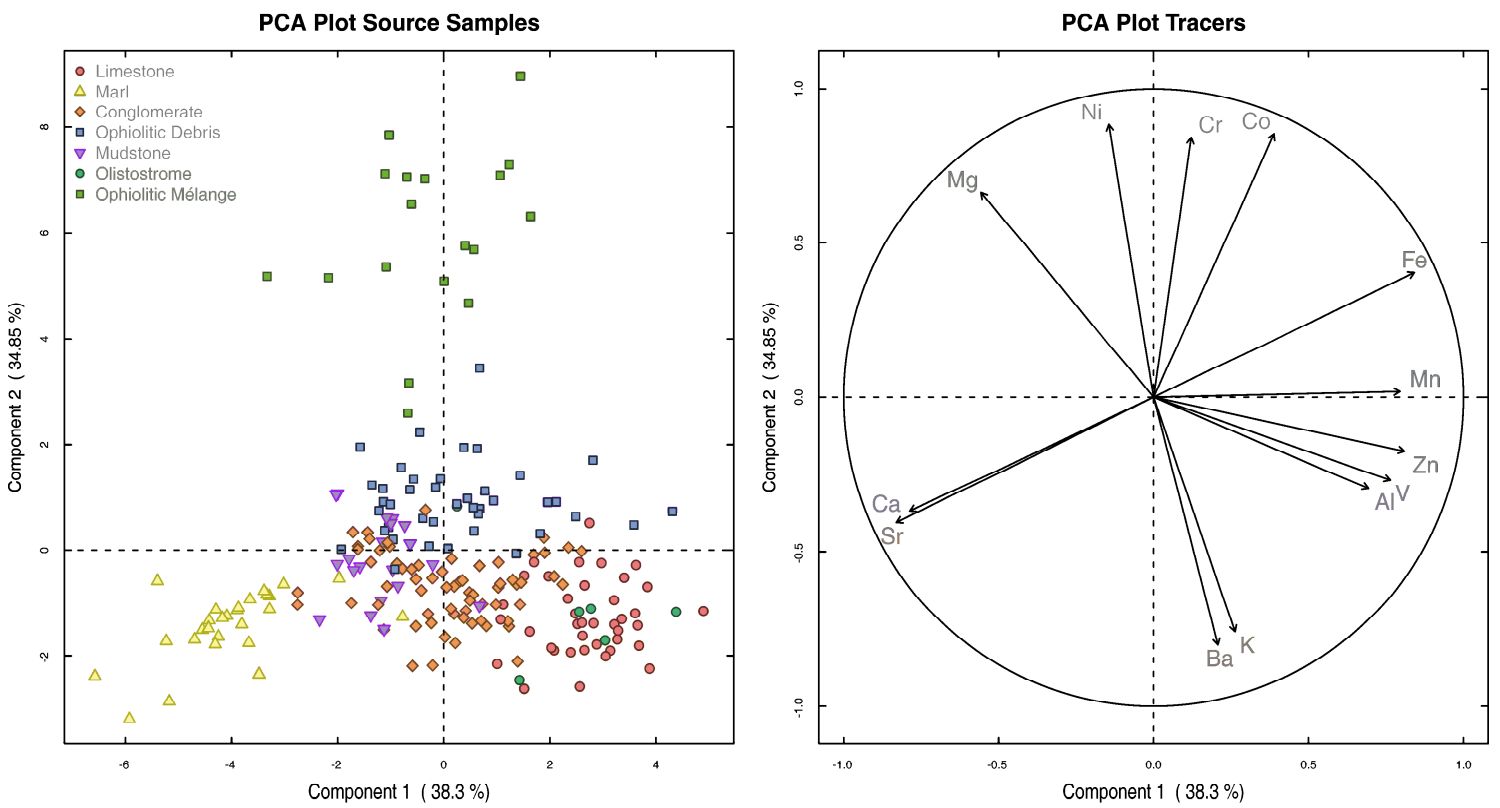

Figure 5 PCA plot of the source samples (left) and tracer loadings (right) on the first two components. 
This manuscript has been published as:

D'Haen K, Verstraeten G, Dusar B, Degryse P, Haex J and Waelkens M. 2012 Unravelling changing sediment sources in a Mediterranean mountain catchment: a Bayesian fingerprinting approach. Hydrological Processes

u
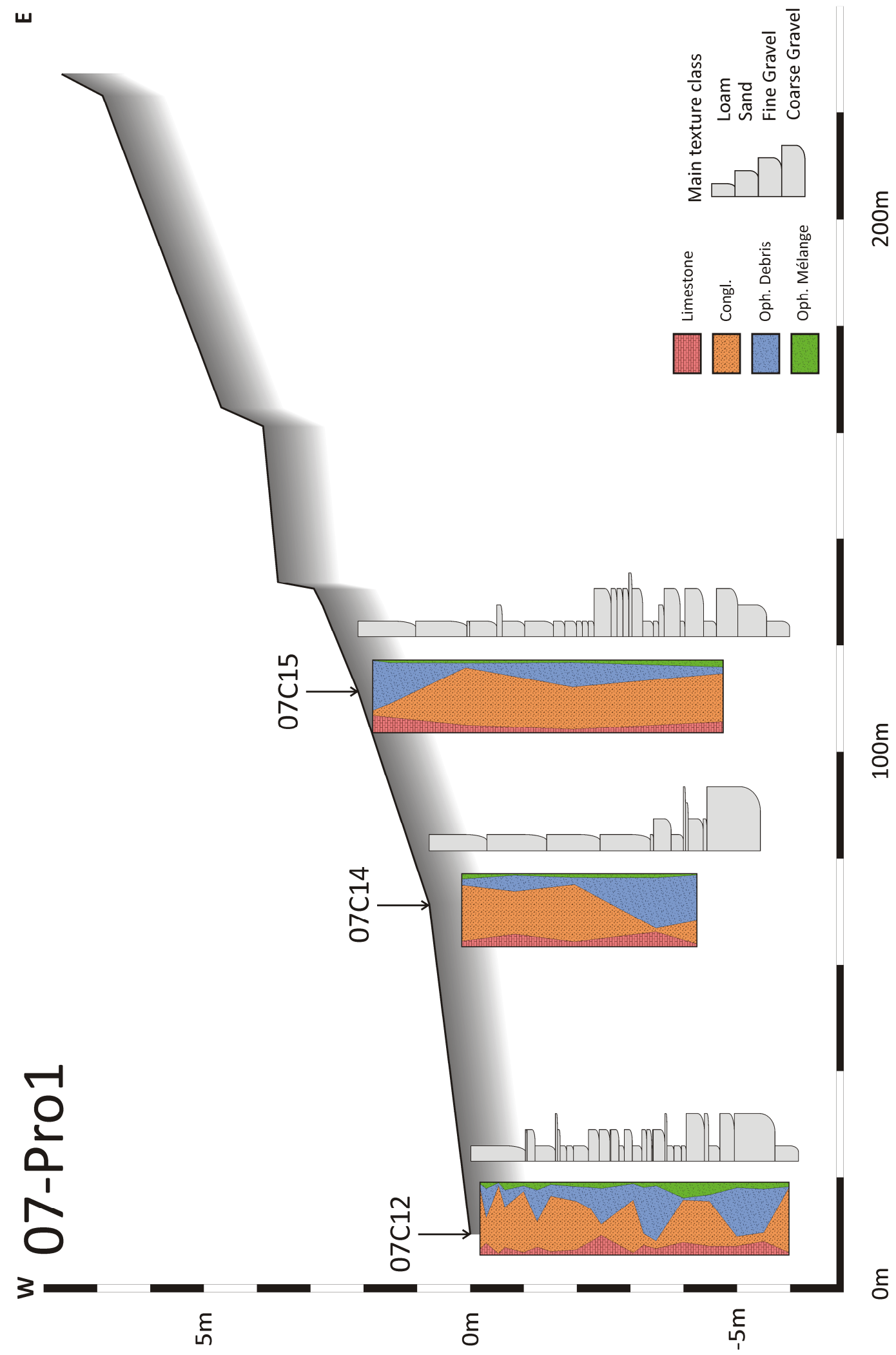

Figure 6 Profile 07-Pro1 with the estimated provenance of the sampled floodplain cores. The mean mixing proportions displayed in the boxes sum op to one. 
This manuscript has been published as:

D'Haen K, Verstraeten G, Dusar B, Degryse P, Haex J and Waelkens M. 2012 Unravelling changing sediment sources in a Mediterranean mountain catchment: a Bayesian fingerprinting approach. Hydrological Processes

$\backsim$

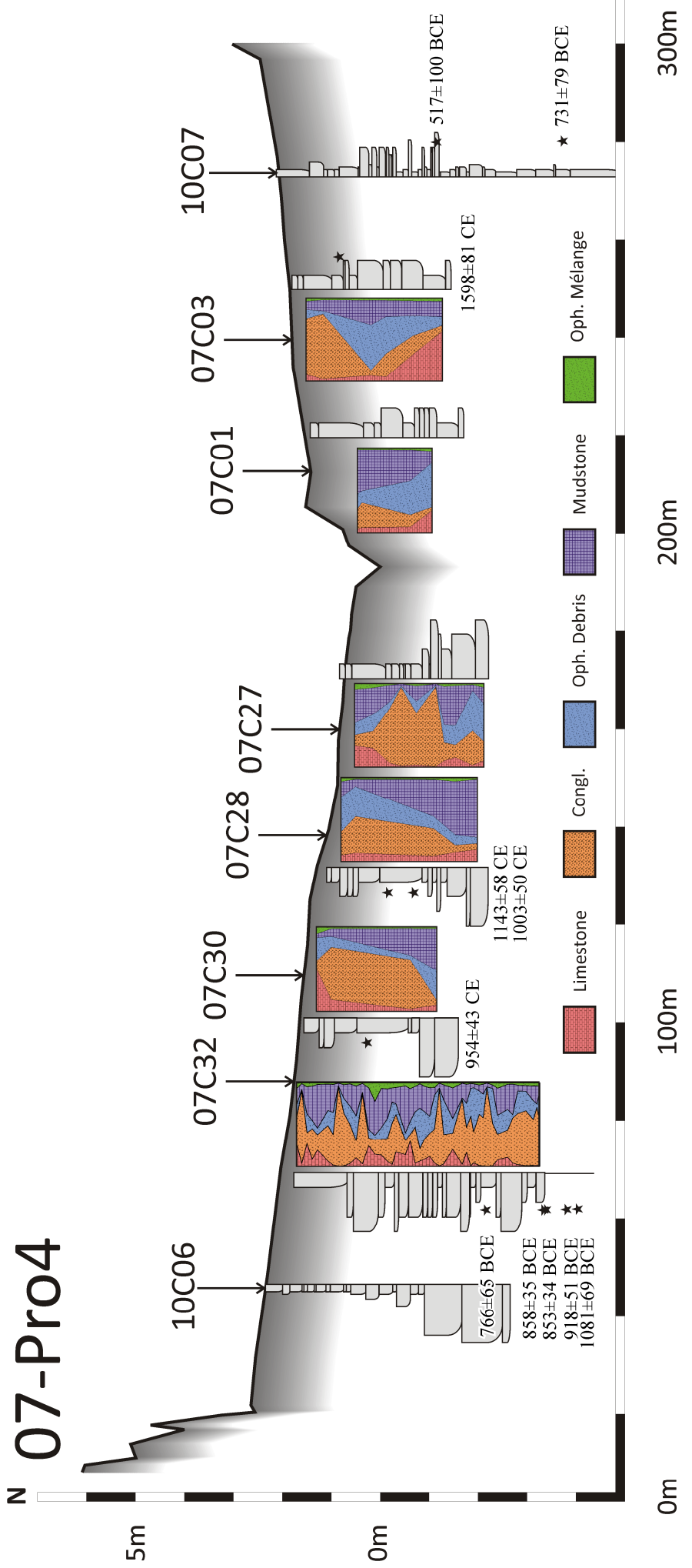

Figure 7 Profile 07-Pro4 with the estimated provenance of the sampled floodplain cores. The mean mixing proportions displayed in the boxes sum op to one. 
This manuscript has been published as:

D'Haen K, Verstraeten G, Dusar B, Degryse P, Haex J and Waelkens M. 2012 Unravelling changing sediment sources in a Mediterranean mountain catchment: a Bayesian fingerprinting approach. Hydrological Processes

$\sim$
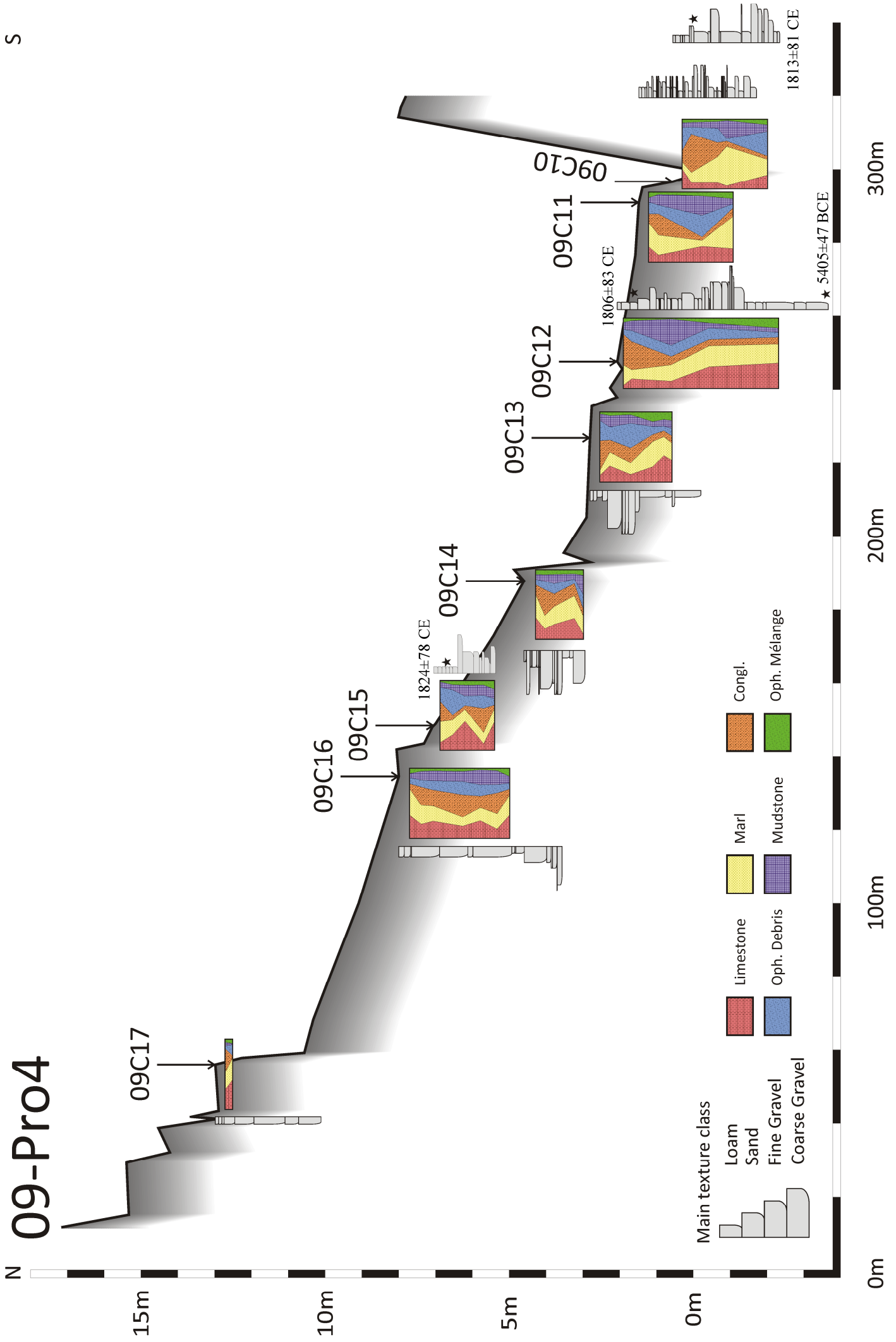

Figure 8 Profile 09-Pro4 with the estimated provenance of the sampled floodplain cores. The mean mixing proportions displayed in the boxes sum op to one. 
This manuscript has been published as:

D'Haen K, Verstraeten G, Dusar B, Degryse P, Haex J and Waelkens M. 2012 Unravelling changing sediment sources in a Mediterranean mountain catchment: a Bayesian fingerprinting approach. Hydrological Processes

$\backsim$

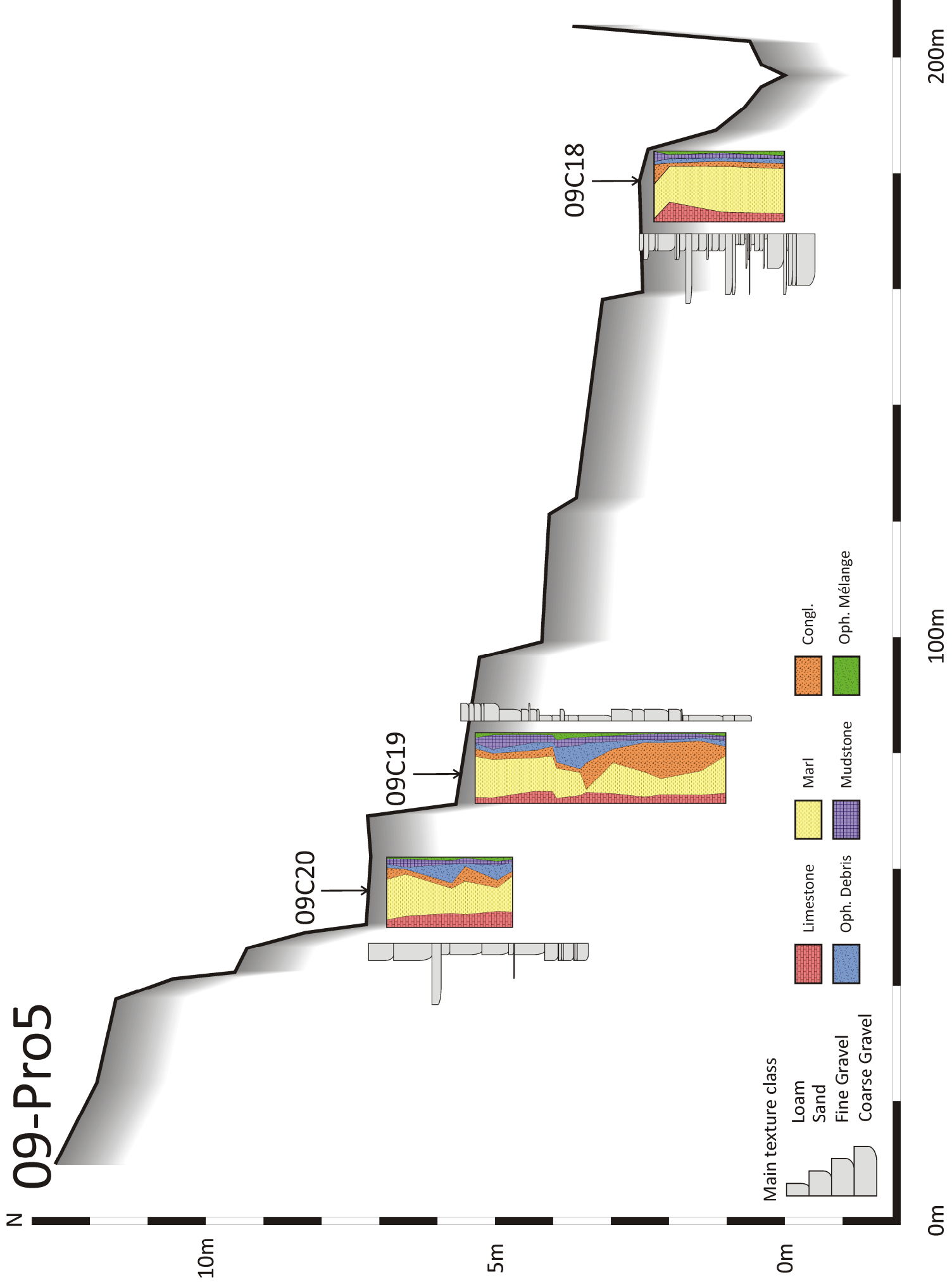

Figure 9 Profile 09-Pro5 with the estimated provenance of the sampled floodplain cores. The mean mixing proportions displayed in the boxes sum op to one. 
This manuscript has been published as:

D'Haen K, Verstraeten G, Dusar B, Degryse P, Haex J and Waelkens M. 2012 Unravelling changing sediment sources in a Mediterranean mountain catchment: a Bayesian fingerprinting approach. Hydrological Processes

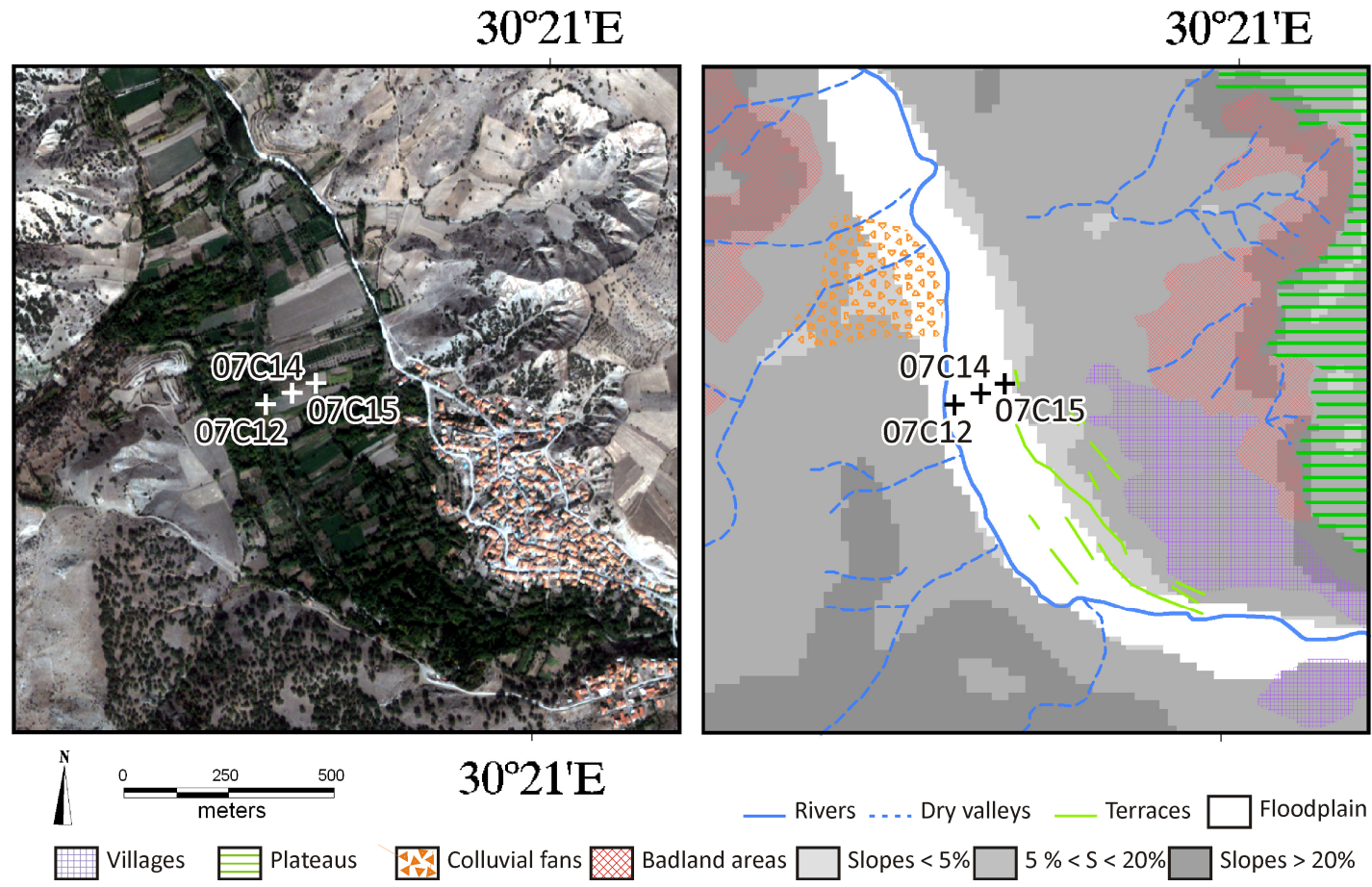

Figure 10 Geomorphic setting of profile 07-Pro1 with a Quickbird image (left) and geomorphological map (right). 
This manuscript has been published as:

D'Haen K, Verstraeten G, Dusar B, Degryse P, Haex J and Waelkens M. 2012 Unravelling changing sediment sources in a Mediterranean mountain catchment: a Bayesian fingerprinting approach. Hydrological Processes

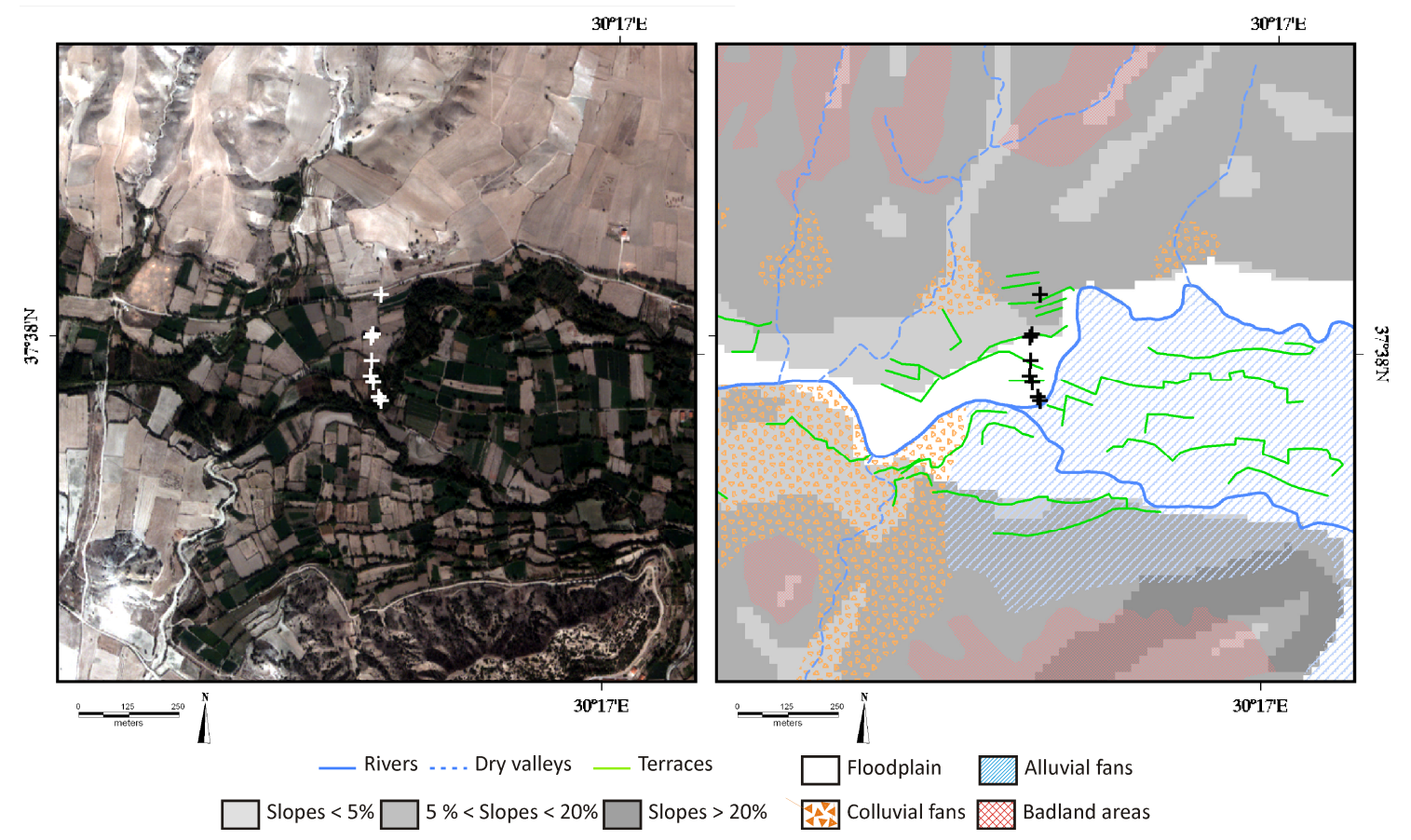

Figure 11 Geomorphic setting of profile 09-Pro4 with a Quickbird image (left) and geomorphological map (right). 
This manuscript has been published as:

D'Haen K, Verstraeten G, Dusar B, Degryse P, Haex J and Waelkens M. 2012 Unravelling changing sediment sources in a Mediterranean mountain catchment: a Bayesian fingerprinting approach. Hydrological Processes

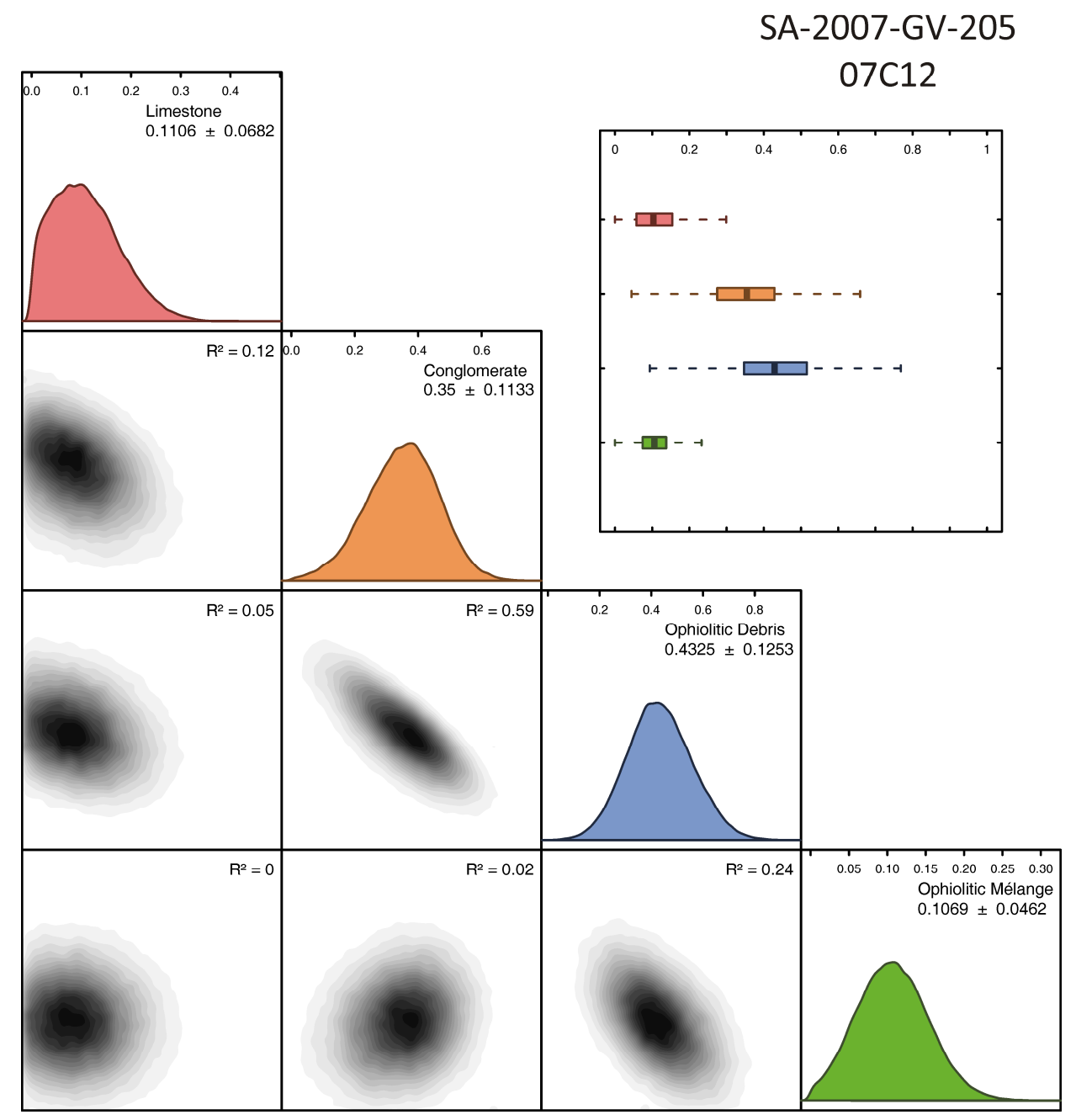

Figure 12 Marginal posterior probability distributions of the mixing proportions of sample SA-2007-205 on the diagonal with an indication of the mean and standard deviation. Correlation between mixing proportions are depicted as 2D-kernel density estimations with an indication of the respective $\mathrm{R}^{2}$ values. Boxplots of the mixing proportions are shown in the right up corner (for details see text). 
This manuscript has been published as:

D'Haen K, Verstraeten G, Dusar B, Degryse P, Haex J and Waelkens M. 2012 Unravelling changing sediment sources in a Mediterranean mountain catchment: a Bayesian fingerprinting approach. Hydrological Processes

\section{SA-2007-GV-738}

$07 C 30$

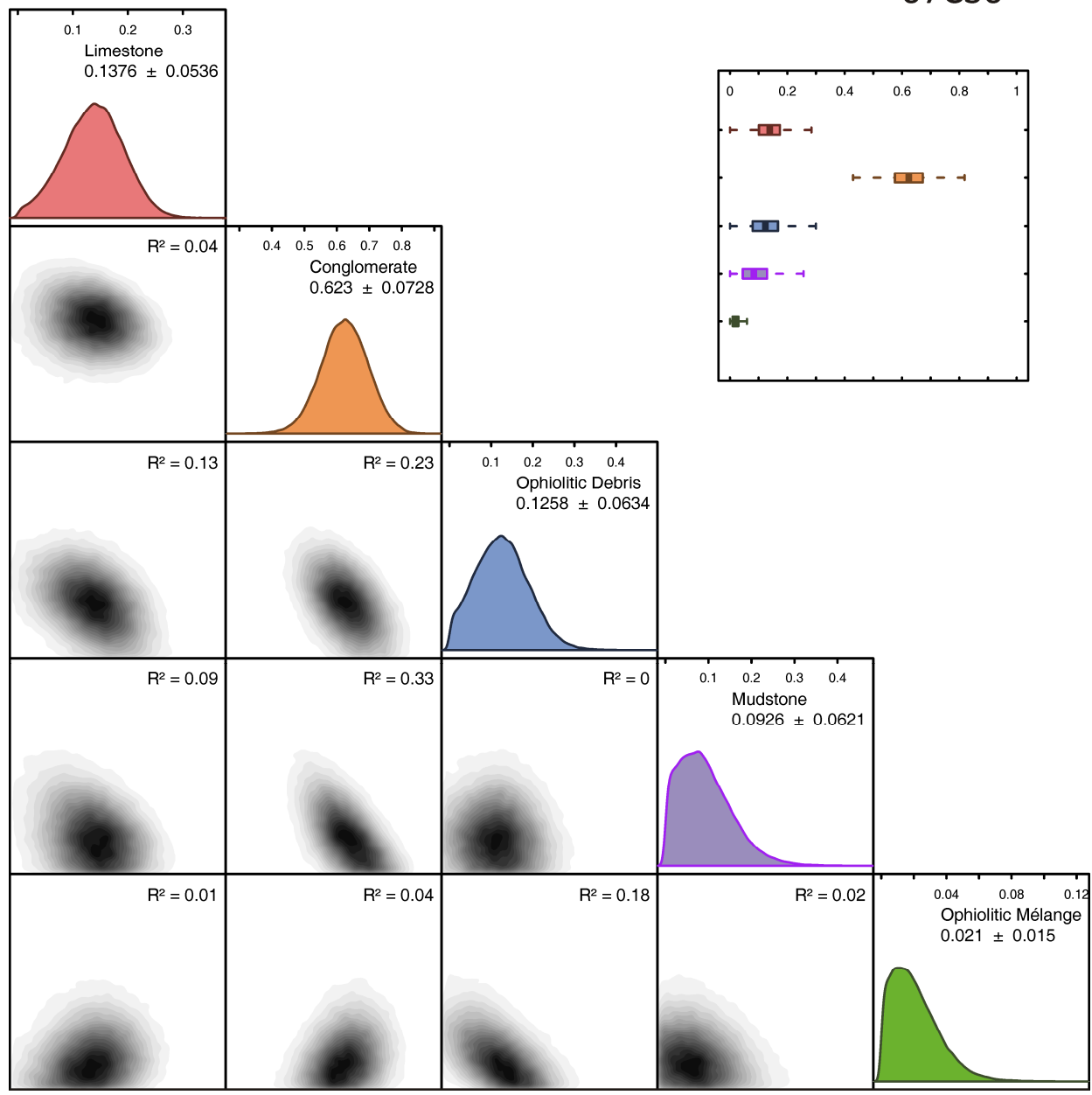

Figure 13 Marginal posterior probability distributions of the mixing proportions of sample SA-2007-738 on the diagonal with an indication of the mean and standard deviation. Correlation between mixing proportions are depicted as 2D-kernel density estimations with an indication of the respective $\mathrm{R}^{2}$ values. Boxplots of the mixing proportions are shown in the right up corner (for details see text). 
This manuscript has been published as:

D'Haen K, Verstraeten G, Dusar B, Degryse P, Haex J and Waelkens M. 2012 Unravelling changing sediment sources in a Mediterranean mountain catchment: a Bayesian fingerprinting approach. Hydrological Processes

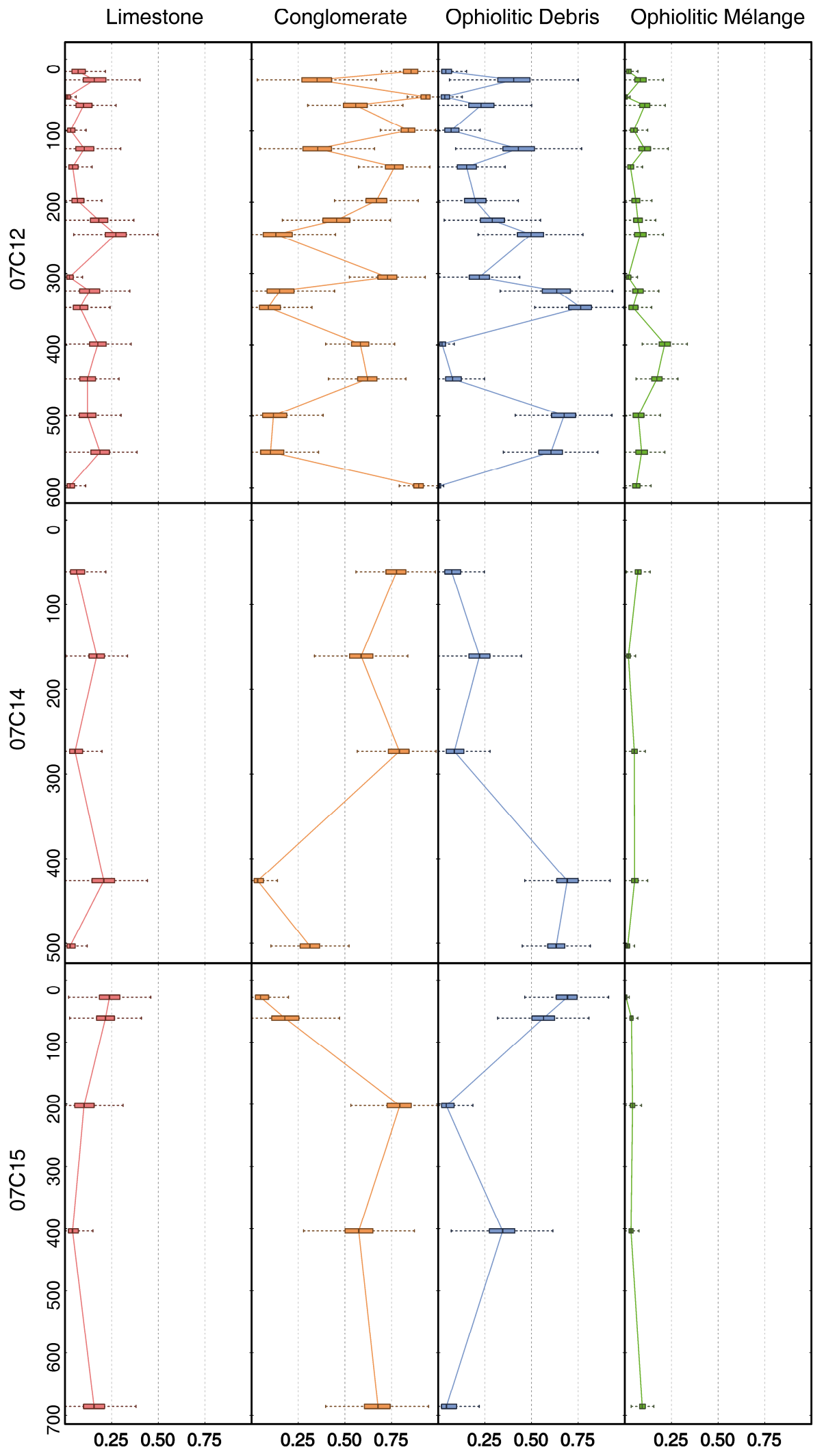

Figure 14 Marginal posterior distributions of the mixing proportions of the floodplain deposits of profile 07-Pro1 presented as boxplots in function of depth $(\mathrm{cm})$. 
This manuscript has been published as:

D'Haen K, Verstraeten G, Dusar B, Degryse P, Haex J and Waelkens M. 2012 Unravelling changing sediment sources in a Mediterranean mountain catchment: a Bayesian fingerprinting approach. Hydrological Processes

\section{Tables}

Table 1 Confusion matrix showing in which class ground truth pixels were classified (in percentages).

Table 2 Table showing overall accuracy of the classification. The producer accuracy indicates the power of the classifier to put a pixel in a class, given that the pixel is actually in that class. The user accuracy on the other hand represents the probability that a classified pixel is in fact in the specified class.

Table 3 Cumulative proportion of source samples classified correctly with Linear Discriminant Analysis.

Table 4 Proportion of upstream area covered by the different lithologies for the four profile locations.

\section{References}

Aitchison J. 1986 Statistical analysis of compositional data Chapman and Hall: New York; 416

Bakker J, Kaniewski D, Verstraeten G, De Laet V and Waelkens M. 2012 Numerically derived evidence for late-Holocene climate change and its impact on human presence in the southwest Taurus Mountains, Turkey. Holocene 22: 425-438. Doi $10.1177 / 0959683611425546$

Bakker J, Paulissen E, Kaniewski D, De Laet V, Verstraeten G and Waelkens M. 2011 Man, vegetation and climate during the Holocene in the territory of Sagalassos, Western Taurus Mountains, SW Turkey. Vegetation History and Archaeobotany: 1-18. 10.1007/s00334-011-0312-4

Collins A, Walling D and Leeks G. 1996 Composite fingerprinting of the spatial source of fluvial suspended sediment: a case study of the Exe and Severn River basins, United Kingdom. Géomorphologie: relief, processus, environnement 2: 41-53.

Collins AL, Walling DE and Leeks GJL. 1997 Use of the geochemical record preserved in floodplain deposits to reconstruct recent changes in river basin sediment sources. Geomorphology 19: 151-167.

Collins AL, Walling DE and Leeks GJL. 1998 Use of composite fingerprints to determine the provenance of the contemporary suspended sediment load transported by rivers. Earth Surface Processes and Landforms 23: 31-52.

Cossart R, Thoms M and Reid M. 2008 Determination and interpretation of sediment provenance in a sedimentary sequence affected by post-depositional changes. In: Schmidt J, Cochrane T, Phillips C, Elliott S, Davies T and Basher L (eds). Sediment 
This manuscript has been published as:

D'Haen K, Verstraeten G, Dusar B, Degryse P, Haex J and Waelkens M. 2012 Unravelling changing sediment sources in a Mediterranean mountain catchment: a Bayesian fingerprinting approach. Hydrological Processes

dynamics in Changing Environments. IAHS Publ. 325. IAHS: Christchurch, New Zealand; 60-67.

D'Haen K, Verstraeten G and Degryse P. 2012 Fingerprinting historical fluvial sediment fluxes. Progress in Physical Geography: Prepublished Feb 3, 2012. $10.1177 / 0309133311432581$

Davis CM and Fox JF. 2009 Sediment Fingerprinting: Review of the Method and Future Improvements for Allocating Nonpoint Source Pollution. Journal of Environmental Engineering-Asce 135: 490-504. 10.1061/(asce)0733-9372(2009)135:7(490)

Dearing JA, Hu YQ, Doody P, James PA and Brauer A. 2001 Preliminary reconstruction of sediment-source linkages for the past $6000 \mathrm{yrs}$ at the Petit Lac d'Annecy, France, based on mineral magnetic data. Journal of Paleolimnology 25: 245-258.

Dusar B, Verstraeten G, D'haen K, Bakker J, Kaptijn E and Waelkens M. 2012 Sensitivity of the Eastern Mediterranean geomorphic system towards environmental change during the Late Holocene: a chronological perspective. Journal of Quaternary Science.

Dusar B, Verstraeten G, Notebaert B and Bakker J. 2011 Holocene environmental change and its impact on sediment dynamics in the Eastern Mediterranean. Earth Science Reviews 108: $137-157$.

Foster IDL, Boardman J and Keay-Bright J. 2007 Sediment tracing and environmental history for two small catchments, Karoo Uplands, South Africa. Geomorphology 90: 126-143. DOI 10.1016/j.geomorph.2007.01.011

Fu B, Newham L and Field J. 2008 Influence of particle size on geochemical suspended sediment tracing in Australia. In: Schmidt J, Cochrane T, Phillips C, Elliott S, Davies $\mathrm{T}$ and Basher L (eds). Sediment dynamics in changing environments. IAHS Publ. 325. IAHS: Christchurch, New Zealand; 23-30.

Gingele FX and De Deckker P. 2005 Clay mineral, geochemical and Sr-Nd isotopic fingerprinting of sediments in the Murray-Darling fluvial system, southeast Australia. Australian Journal of Earth Sciences 52: 965-974. Doi 10.1080/08120090500302301

Hamlin R, Woodward J, Black S and Macklin M. 2000 Sediment fingerprinting as a tool for interpreting long-term river activity: the Voidomatis Basin, North-west Greece. In: Foster IDL (ed) Tracers in Geomorphology. John Wiley \& Sons Ltd: Chichester; 473502.

Hoffmann T, Erkens G, Gerlach R, Klostermann J and Lang A. 2009 Trends and controls of Holocene floodplain sedimentation in the Rhine catchment. Catena 77: 96-106.

Kaniewski D, De Laet V, Paulissen E and Waelkens M. 2007a Long-term effects of human impact on mountainous ecosystems, western Taurus Mountains, Turkey. Journal of Biogeography 34: 1975-1997. DOI 10.1111/j.1365-2699.2007.01753.x

Kaniewski D, Paulissen E, De Laet V, Dossche K and Waelkens M. 2007b A high-resolution Late Holocene landscape ecological history inferred from an intramontane basin in the Western Taurus Mountains, Turkey. Quaternary Science Reviews 26: 2201-2218. DOI 10.1016/j.quascirev.2007.04.015

Kaniewski D, Paulissen E, De Laet V and Waelkens M. 2008 Late Holocene fire impact and post-fire regeneration from the Bereket basin, Taurus Mountains, southwest Turkey. Quaternary Research 70: 228-239. DOI 10.1016/j.yqres.2008.04.002

Krishnappan BG, Chambers PA, Benoy G and Culp J. 2009 Sediment source identification: a review and a case study in some Canadian streams. Canadian Journal of Civil Engineering 36: 1622-1633. Doi 10.1139/L09-110

Macklin MG and Lewin J. 2008 Alluvial responses to the changing Earth system. Earth Surface Processes and Landforms 33: 1374-1395. Doi 10.1002/Esp.1714 
This manuscript has been published as:

D'Haen K, Verstraeten G, Dusar B, Degryse P, Haex J and Waelkens M. 2012 Unravelling changing sediment sources in a Mediterranean mountain catchment: a Bayesian fingerprinting approach. Hydrological Processes

Minella JPG, Walling DE and Merten GH. 2008 Combining sediment source tracing techniques with traditional monitoring to assess the impact of improved land management on catchment sediment yields. Journal of Hydrology 348: 546-563. DOI 10.1016/j.jhydrol.2007.10.026

Owens PN and Walling DE. 2002 Changes in sediment sources and floodplain deposition rates in the catchment of the River Tweed, Scotland, over the last 100 years: The impact of climate and land use change. Earth Surface Processes and Landforms 27: 403-423. Pii 10.1002/Esp.327

Owens PN, Walling DE and Leeks GJL. 1999 Use of floodplain sediment cores to investigate recent historical changes in overbank sedimentation rates and sediment sources in the catchment of the River Ouse, Yorkshire, UK. Catena 36: 21-47.

Paulissen E, Poesen J, Govers G and de Ploey J. 1993 The physical environment at Sagalassos (Western Taurus, Turkey). A reconnaissance survey. In: Waelkens $\mathrm{M}$ and Poblome $\mathrm{J}$ (eds) Sagalassos II, Report on the Third Excavation campaign of 1992. Leuven University Press: Leuven; 229-248.

Price SP and Scott B. 1994 Fault-block rotations at the edge of a zone of continental extension; southwest Turkey. Journal of Structural Geology 16: 381-392. 10.1016/0191-8141(94)90042-6

Raftery AE and Lewis SM. 1996 Implementing MCMC. In: Gilks WR, Richardson S and Spiegelhalter DJ (eds) Markov chain Monte Carlo in practice. Chapman and Hall: London; 115-130.

Senel M. 1997 1:100 000 scale geological maps of Isparta-J10 Quadrangle. Ankara: General Directorate of Mineral Research and Exploitation.

Van den Meersche K, Soetaert K and Middelburg JJ. 2008 A Bayesian compositional estimator for microbial taxonomy based on biomarkers. Limnology and Oceanography: Methods 6: 190-199.

Verstraeten G, Lang A and Houben P. 2009a Human impact on sediment dynamics quantification and timing Introduction. Catena 77: 77-80. DOI 10.1016/j.catena.2009.01.005

Verstraeten G, Rommens T, Peeters I, Poesen J, Govers G and Lang A. 2009b A temporarily changing Holocene sediment budget for a loess-covered catchment (central Belgium). Geomorphology 108: 24-34. DOI 10.1016/j.geomorph.2007.03.022

Waelkens M, Paulissen E, Vermoere M, Degryse P, Celis D, Schroyen K, De Cupere B, Librecht I, Nackaerts K, Vanhaverbeke H, Viaene W, Muchez P, Ottenburgs R, Deckers S, Van Neer W, Smets E, Govers G, Verstraeten G, Steegen A and Cauwenberhs K. 1999 Man and environment in the territory of Sagalassos, a classical city in SW Turkey. Quaternary Science Reviews 18: 697-709.

Walling DE, Owens PN, Foster IDL and Lees JA. 2003 Changes in the fine sediment dynamics of the Ouse and Tweed basins in the UK over the last 100-150 years. Hydrological Processes 17: 3245-3269. Doi 10.1002/Hyp.1385

Zhang K, Liu K and Yang J. 2004 Asymmetrical valleys created by the geomorphic response of rivers to strike-slip fault. Quaternary Research 62: 310-315. 
This manuscript has been published as:

D'Haen K, Verstraeten G, Dusar B, Degryse P, Haex J and Waelkens M. 2012 Unravelling changing sediment sources in a Mediterranean mountain catchment: a Bayesian fingerprinting approach. Hydrological Processes

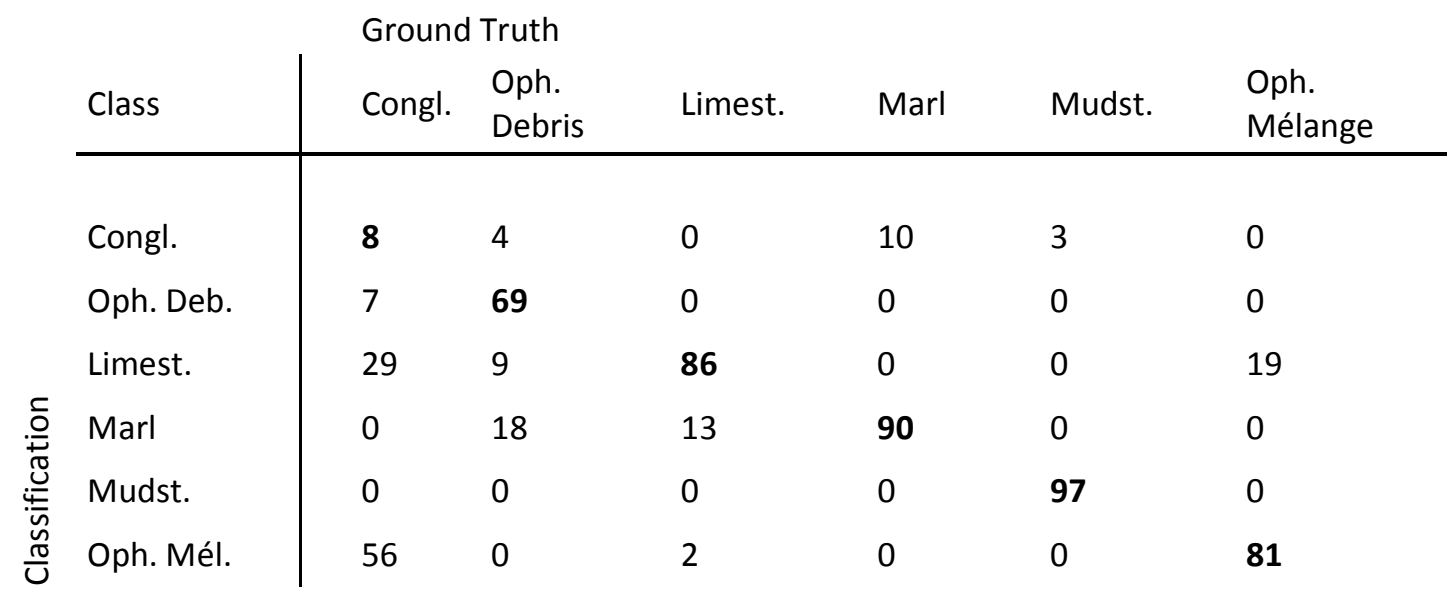

Table 1 Confusion matrix showing in which class ground truth pixels were classified (in percentages).

\begin{tabular}{lllll}
\hline Class & $\begin{array}{l}\text { Producer } \\
\text { Accuracy } \\
(\%)\end{array}$ & $\begin{array}{l}\text { User } \\
\text { Accurarcy } \\
(\%)\end{array}$ & $\begin{array}{l}\text { Producer } \\
\text { Accuracy } \\
\text { (pixels) }\end{array}$ & $\begin{array}{l}\text { User } \\
\text { Accurarcy } \\
\text { (pixels) }\end{array}$ \\
\hline Conglomerate & 8 & 29 & $7 / 86$ & $7 / 24$ \\
Ophiolitic Debris & 69 & 92 & $72 / 104$ & $72 / 78$ \\
Limestone & 86 & 62 & $89 / 104$ & $89 / 144$ \\
Marl & 90 & 75 & $95 / 105$ & $95 / 127$ \\
Mudstone & 97 & 100 & $109 / 112$ & $109 / 109$ \\
Ophiolitic Mélange & 81 & 64 & $90 / 111$ & $90 / 140$ \\
& & & & \\
\hline
\end{tabular}

Table 2 Table showing overall accuracy of the classification. The producer accuracy indicates the power of the classifier to put a pixel in a class, given that the pixel is actually in that class. The user accuracy on the other hand represents the probability that a classified pixel is in fact in the specified class. 
This manuscript has been published as:

D'Haen K, Verstraeten G, Dusar B, Degryse P, Haex J and Waelkens M. 2012 Unravelling changing sediment sources in a Mediterranean mountain catchment: a Bayesian fingerprinting approach. Hydrological Processes

\begin{tabular}{|c|c|c|c|c|c|c|c|c|}
\hline Tracer & Limestone & Marl & Conglomerate & $\begin{array}{l}\text { Ophiolitic } \\
\text { Debris }\end{array}$ & Mudstone & Olistostrome & $\begin{array}{l}\text { Ophiolitic } \\
\text { Mélange }\end{array}$ & Total \\
\hline Co & 0 & 78 & 86 & 56 & 0 & 0 & 89 & 54 \\
\hline $\mathrm{Sr}$ & 90 & 93 & 73 & 51 & 15 & 0 & 89 & 68 \\
\hline $\mathrm{Al}$ & 87 & 93 & 73 & 54 & 35 & 0 & 89 & 70 \\
\hline $\mathrm{Ca}$ & 90 & 93 & 80 & 56 & 35 & 0 & 89 & 73 \\
\hline $\mathrm{Mg}$ & 92 & 93 & 80 & 76 & 35 & 0 & 89 & 77 \\
\hline K & 87 & 96 & 77 & 78 & 35 & 17 & 89 & 77 \\
\hline $\mathrm{Cr}$ & 90 & 96 & 82 & 76 & 50 & 0 & 89 & 79 \\
\hline $\mathrm{Ba}$ & 87 & 96 & 80 & 78 & 55 & 17 & 83 & 79 \\
\hline $\mathrm{Fe}$ & 87 & 96 & 82 & 78 & 65 & 17 & 94 & 82 \\
\hline V & 87 & 96 & 83 & 78 & 60 & 17 & 83 & 81 \\
\hline $\mathrm{Ni}$ & 87 & 96 & 83 & 78 & 85 & 17 & 89 & 83 \\
\hline $\mathrm{Mn}$ & 92 & 96 & 88 & 78 & 85 & 33 & 83 & 86 \\
\hline $\mathrm{Zn}$ & 90 & 96 & 88 & 76 & 85 & 33 & 94 & 86 \\
\hline
\end{tabular}

Table 3 Cumulative proportion of source samples classified correctly with Linear Discriminant Analysis.

\begin{tabular}{lllllll}
\hline Profile & Limestone & Marl & Congl. & Oph. Debris & Mudstone & $\begin{array}{l}\text { Oph. } \\
\text { Mélange }\end{array}$ \\
\hline 07-Pro1 & 0.47 & 0.00 & 0.28 & 0.14 & 0.00 & 0.11 \\
07-Pro4 & 0.34 & 0.00 & 0.23 & 0.10 & 0.22 & 0.12 \\
09-Pro4 & 0.30 & 0.17 & 0.20 & 0.06 & 0.14 & 0.13 \\
09-Pro5 & 0.25 & 0.31 & 0.17 & 0.05 & 0.12 & 0.11 \\
& & & & & & \\
\hline
\end{tabular}

Table 4 Proportion of upstream area covered by the different lithologies for the four profile locations. 